\title{
Differently unequal Zooming-in on the distributional dimensions of the crisis in euro area countries
}

\author{
Marco D'Errico \\ University of Milano-Bicocca
}

\author{
Corrado Macchiarelli ${ }^{1}$ \\ Brunel University London e London School of Economics
}

\author{
Roberta Serafini \\ European Central Bank
}

\begin{abstract}
This paper discusses how income inequality developed during the current crisis in euro area countries, as well as the role played by each income source. Based on an extended definition of income - including additional components which do not appear in the standard Eurostat definitions - we complement the information provided by the Gini index and quantile ratios by computing an alternative inequality indicator, developed by Zenga (2007), and its decomposition by income source. While broadly confirming the distributional effect of the crisis documented in previous studies, we find that in specific countries the level of inequality appears higher when alternative measures are taken into account, and that the rise of inequality since 2008 has not been as modest as previous studies would suggest. The paper further looks at how the distribution of income has evolved during the crisis by income quantile groups (i.e. 'zooming-in'). The results point to varying contribution of labour income in 2011 compared to 2007. In addition, while the impact of individual households' characteristics shows a non-linear pattern across income quantile groups before the crisis, such dispersion has decreased in 2011. We argue that, on the basis of our analysis, not only euro area countries are "differently unequal" in that inequality has developed in a very peculiar way in different countries, but also because it needs to be tackled at a finer level of analysis.
\end{abstract}

\section{Introduction}

The 2007-2008 financial crisis marked the start of a severe and protracted recession in both Europe and the US. A number of euro area countries experienced the deepest downturn since the Great Depression; at the same time, the negative growth prospects were reinforced by the sovereign debt crisis which triggered considerable fiscal consolidation efforts in vulnerable euro area economies. Not surprisingly, how these developments have affected income distribution has recently come back to the attention of academics and policy makers.

Income distribution developments are often seen as mainly relevant from a social cohesion point of view, with negligible (if any) direct impact on economic performance. Yet, a large number of theoretical and empirical studies shows that income distribution does matter for subsequent growth. According to Alesina and Perotti (1996), highly unequal societies are characterised by considerable socio-political instability, as well as by high uncertainty in the protection of property rights, which discourage investment and inhibit growth (see also Keefer and Knack, 2002). At the same time, when credit constraints are binding, a higher degree of income "polarisation" would result into a higher percentage of individuals in the lower tail of the distribution whose income is below the cost of education, thereby reducing the incentive to invest in human capital accumulation with ultimate detrimental effects on growth. The latter effect would be significant in

\footnotetext{
${ }^{1}$ Corresponding author, Brunel University London, Uxbridge, UB8 3PH, United Kingdom, Tel: -44 (0)189 5267223 , E-mail: c.macchiarelli@lse.ac.uk. The authors are grateful to Michele Zenga, Eddie Gerba, Angelo Martelli and Alberto Arcagni for constructive comments and discussions. The paper also benefited from comments provided by Paul De Grauwe, Waltraud Schelke and from other participants at an internal seminar organized by the LSE European Institute, together with participants at an internal seminar at the European Central Bank and the 2014 International Conference on Macroeconomic Analysis and International Finance in Crete. The authors also acknowledge comments from Fabien Labondance and an anonymous referee. The views expressed are those of the authors and do not necessarily reflect those of the European Central Bank.
} 
rich economies (see for instance Perotti 1993 and 1996), and particularly when considering that higher levels of inequality are normally associated with lower social and economic mobility, and therefore with lower investment in education generation after generation. Finally, in more unequal societies, interests groups are more prone to engage in rent-seeking activities which are harmful for growth (Perotti, 1996 and Benabou, 1996). At the same time, however, a number of studies points at a positive impact of inequality on growth prospects ( $\mathrm{Li}$ and Zou, 1998; Forbes, 2000). According to this literature, when favouring the rich, inequality would spur aggregate savings and growth. Furthermore, a certain degree of inequality may induce individuals to increase their effort to access higher income levels.

Overall, whether inequality is good or bad for growth is still a debated issue. Clearly, the answer to this question is not independent of the stage of economic development. According to Galor and Moav (2004), at earlier stages of development, physical capital is relatively scarce and therefore inequality would have a positive impact on growth by channelling resources towards those segments of the population with a higher propensity to save. The opposite would hold at later stages of development, in which human capital accumulation becomes the main engine of growth, and inequality would exacerbate the adverse effect of credit constraints on human capital investment and growth. At the same time, for a given level of economic development, changes in overall inequality - however measured - may correspond to very different scenarios, and therefore have very different implications for growth, depending on what portions of the income distribution are affected. Based on data from the Luxembourg Income Study, Voitchovsky (2005) shows that while top end inequality is positively related with economic performance, inequality at the bottom end proves to be harmful for growth. These offsetting effects may explain the fact that sometimes inequality - captured by summary statistics such as the Gini coefficient - appears insignificant in growth equations, calling for analyses looking at a wide array of indicators at a more granular level. Given the significance of inequality on growth, the aim of this paper is to look at how inequality has evolved in euro area countries since the start of the crisis and - more importantly - to shed light on which portions of the income distribution are actually driving the observed dynamics. This has the potential to help identify common patterns across countries and to distinguish those cases where inequality can be considered "good" or "bad" - i.e. whether inequality is likely to be conducive to higher growth or unfavourably affect economic performance. This issue appears particularly important in the current juncture, as the shape of income distribution - in principle can either reinforce the persistence of a recession phase or be among the driving forces behind a faster recovery.

A growing number of empirical studies have recently explored the distributional impact of the crisis by focusing on a wide array of variables such as income, earnings, consumption expenditure and wealth (Jenkins et al.,2011; Heathcote et al., 2010; Petev et al., 2011; Perri and Steinberg,2012). In all of these studies, developments in income distribution are normally discussed with reference to a standard set of indicators, such as the average and median income, the Gini coefficient, the poverty rate. While undeniably useful, these indicators do not allow properly taking into account the relationship between the lower tail and the upper tail of the income distribution. In particular, Heatcote et al. (2010) present empirical results of the evolution of inequality in the United States for the years 1967-2006, suggesting that inequality may have several dimensions. They find that wage inequality presents a steady increase in the course of the years considered and that taxes and transfers have had an impact on the lower tail of the distribution (the poorest) but little effect on aggregated inequality. Perry and Steinberg (2012) explored the way the crisis has impacted economic inequality in the United States, analysing, among the others, earnings, disposable income, consumption and wealth: they argue that a more in-depth analysis on the different income levels is key to draw a clearer picture. Moreover, the same authors argue that redistribution policies made it possible to contain falloffs in consumption for the bottom quintile of the distribution.

All these studies point to the methodological need to investigate the impact of the recent economic crisis along several (micro) dimensions and variables. Moreover, we believe that such an analysis 
needs to be done within the euro area context as well, as it could assist the identification of common patterns or, vice versa, heterogeneous recovery dynamics. Due to the heterogeneity of the countries belonging to the euro area, we advocate a country-based analysis is fundamental to better understand how the crisis has impacted inequality developments in the Eurozone. In addition, the studies mentioned above suggest the need of breaking down the analysis by studying the effects of individual income levels and family types. That is what we propose to do in this paper.

Based on household level data from the EU Survey of Income and Living Conditions (EU-SILC), the paper looks for alternative inequality indicators. The analysis is performed for the cross-sections 2004 to 2011. In particular, the paper makes use of a (relatively) new (albeit, admittedly, less known) indicator, the Zenga index (2007), which allows to detect, with identical receptivity, deviations from equality in any parts of the distribution (see Section 4). The latter indicator is used to complement the information provided by the Gini index - thereby allowing a comparison with the results available in the literature. Following the approach proposed in Lerman and Yitzhaki (1984; 1985) and in Zenga and Radaelli (2007), the evolution of the Gini and Zenga indexes is further decomposed into the contribution to overall inequality coming from single income sources. This allows to quantitatively assess how inequality developed as a result of the economic crisis, especially in those economies which were more hardly hit. Beside an analysis on baseline disposable income, inequality is further analysed with reference to an extended income definition, including additional income components, some of which being particularly relevant in the current conjuncture.

Despite providing an alternative income definition, the novelty of our approach, however, stands in looking at how the distribution of income has evolved during the crisis by income quantile groups (i.e. referred to as 'zooming-in'). An analysis of income inequality as such a granular level is indeed made possible by the use of the Zenga index (2007) and its linearity property (see Section 4). Digging into inequality dynamics is key, especially since movements at different levels of the distribution may not necessarily translate into higher (lower) inequality overall, and in particular if larger movements from people in the mid into the lower end of the distribution are compensated by a relative depletion of people at the top end of the distribution. It is worth noting, in fact, that increases (decreases) of inequality measures, however defined, do not necessarily mean a worsening (improvement) in the distribution of income. At one extreme, inequality may increase as a result of a higher share of population moving to higher income levels, the position of the lower tail of the distribution being unchanged. Such an outcome may be actually read as a Pareto improvement. Conversely, changes in inequality over time may be driven by the poorest segments of the population. At those extremes, policy implications would be very different. Therefore, in order to be able to capture different dimensions of inequality it is necessary to take a closer look at i) a wider array of indicators, ii) the contribution of each income sources and iii) observe such contribution not only in the aggregate, but also by population sub-groups. In addition, and as discussed previously, previous studies have shown that the crisis has had different effects on income inequality in different countries. We argue that such country-specific dynamics needs to be brought to an even finer level of analysis. In fact, we find that the inequality dynamics, and particularly pre-and post-crisis comparisons, are extremely articulated. Our analysis based on the decomposition of different indexes by sources, shows quite clearly that inequality patterns are specific to each country/source/income level combination. In particular, the results suggest that the distributional impact of the crisis has evolved in quite different ways in several countries and 'zooming-in' may help capture some of this heterogeneity. We argue that, on the basis of our analysis, not only euro area countries are "differently unequal" in that inequality has developed in a very peculiar way in different countries, but also because it needs to be tackled at a finer level of analysis. In this respect, redistribution policies need to be fine-tuned along these lines, rather than addressing the problem from an aggregate viewpoint.

The remainder of the paper is organized as follows. Section 2 and 3 outline the main features of the dataset and possible statistical issues; they further discuss the extended income definition used in 
the paper. Section 4 introduces the alternative inequality indicator (Zenga, 2007) and presents its methodological decomposition, compared to the Gini index. Section 5 outlines the main results, by further tackling the distributional impact of the crisis for specific income levels. Section 6 concludes.

\section{Data}

We use net income flows data from the Eurostats Survey of Income and Living Conditions for 12 euro area countries over the period 2004-2011, allowing to cover the period immediately preceding the financial crisis and the following economic downturn. The euro area countries considered are (in alphabetical order): Austria (AT), Belgium (BE), Cyprus (CY), Germany (DE), Spain (ES), Finland (FI), France (FR), Greece (GR), Ireland (IE), Italy (IT), the Netherlands (NL), Portugal $(\mathrm{PT})^{2}$

The EU-SILC provides the longest time series of comparable and consistently defined individual level data for income and living conditions available for the euro area. One of the attractive features of the EU-SILC, compared to other surveys, is that it provides not only details on each individual and households' characteristics (i.e. family composition, etc.), but also information on the level of household income and measures of households' wealth such as households' ability to face unexpected financial expenses, mortgage burden, etc. Cross-sectional data are available for total household gross and net income. Table 1 further clarifies the difference between gross and net incomes. The former is defined as the sum for all household's members of gross personal income components (gross employee cash or near cash income) plus gross income components at household level. Net (or disposable) income equals gross income minus tax (including "Regular taxes on wealth", "Regular inter-household cash transfer paid" and "Tax on income and social insurance contributions"; see Table 1). Income is available for almost all countries over the whole sample period (for Ireland the last available wave in the EU-SILC was 2010). Summary statistics on the data employed (gross and net incomes) are reported in Table lA (Annex 1). The only restriction imposed to the data is that observations for which income sources are available should report total incomes as well, and vice versa. Yet, this leaves a consistent number of observations. ${ }^{3}$ In the following sections, the evolution of inequality is presented normalized onto pre-crisis averages (2005-07). Normalizing income is useful to deal with the fact that inequality may have been characterized as "bubbly" in the pre-crisis period in some countries. For further comparisons, the results for inequality indexes over the whole sample period 2004-11 are anyway provided in Annex 1 (Figure 1A), where available.

Comparing income inequality across countries requires the use of scaling factors, which weight households' income according to their composition. The household weighting scheme adopted here is based on equivalence scales measures. The intuition behind using weighting schemes is that of accounting for income to grow within each additional household member in a non-proportional way (see Atkinson et al., 1995; World Bank, 2002). Following a standard practice, we rely on the OECD-modified scale assuming, for instance, that a household of two adults and two children has different needs (e.g., roughly twice as much) as one composed of a single person. While this choice clearly depends on technical assumptions about economies of scale, as well as on judgments about the priority assigned to the needs of different individuals - such as children or the elderly - it also

\footnotetext{
${ }^{2}$ Excluding data prior to 2004 is motivated by overcoming major data missing. While the EU-SILC is potentially concerned with a wider set of countries, we focus on those countries whose dynamics are more relevant to dynamics of the euro area as a whole, thus covering "program and vulnerable countries" (Cyprus (CY), Spain (ES), Greece (GR), Ireland (IE), Italy (IT), Portugal (PT)) and "northern countries" (Austria (AT), Belgium (BE), Germany (DE), Finland (FI), France (FR), the Netherlands (NL)).

${ }^{3}$ Given the consistency check between sources and total income, the data coverage for our extended income may vary, depending on the coverage of the two new income sources considered. In particular, this availability reduces to Cyprus, Germany and the Netherlands: 2005-11; Spain, France, Greece, Italy and Portugal: 2007-11. For Austria, Belgium, Finland and Ireland, extended disposable income is available over the whole sample period, 2004-11.
} 
allows comparability with other studies and official publications (e.g., Eurostat). In this way, each household type in the population is assigned a value in proportion to its (assumed) produced income, mainly taking into account the size of the household and the age of its members - whether they are adults or children (see OECD, 2008; 2011).

For each household, total disposable and gross incomes are imputed consistently with the underlying income components, as described by the Eurostat's EU-SILC User Guide. In order to allow for a decomposition of total income (either gross or net) by components, income sources are partitioned according to (cash and non-cash) labour income, cash transfers, other sources of income, and direct taxes (the latter for net income, only). Within the labour income component, we further distinguish among income from employment, income from self-employment and non-cash labour income. Following Jenkins et al. (2011) we define cash transfers, including all cash benefits from the government plus transfers (such as state retirement pensions), and other income sources (mainly including income from investment and savings).,

Table $\mathbf{l}$ - Income definitions

\begin{tabular}{|c|c|c|c|}
\hline & \multirow{19}{*}{ 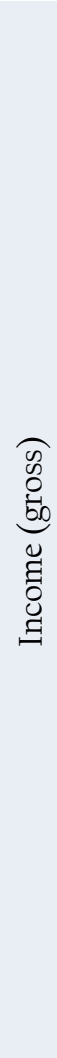 } & Paper definition of disposable income & EU-SILC definitions \\
\hline & & Labour income & Gross employee cash or near cash income \\
\hline & & $\begin{array}{l}\text { Labour income from } \\
\text { self-employment }\end{array}$ & $\begin{array}{l}\text { Gross cash benefits or losses from self- } \\
\text { employment (including royalties) }\end{array}$ \\
\hline & & Non-cash labour income & $\begin{array}{l}\text { Company car (from 2007, before it is gross non-cash } \\
\text { employee income, see Eurostat) }\end{array}$ \\
\hline & & Cash tranfers & Unemployment benefits \\
\hline & & & Old-age benefits \\
\hline & & & Survivor' benefits \\
\hline & & & Sickness benefits \\
\hline (ี) & & & Disability benefits \\
\hline$\Xi$ & & & Education-related allowances \\
\hline हี & & & Family/children related allowances \\
\hline.$\Xi$ & & & Social exclusion not elsewhere classified \\
\hline & & & Housing allowances \\
\hline$\infty$ & & & Regular inter-household cash transfers received \\
\hline$\frac{3}{2}$ & & & Income received by people aged under 16 \\
\hline$\ddot{\theta}$ & & Other income & Income from rental of a property or land \\
\hline & & & $\begin{array}{l}\text { Interests, dividends, profit from capital } \\
\text { investments in unincorporated business }\end{array}$ \\
\hline & & & $\begin{array}{l}\text { Pensions received from individual private plans } \\
\text { (other than those covered under ESSPROS) }\end{array}$ \\
\hline & & Interests on Mortgages & Interest paid on mortgage \\
\hline & & Taxes & Regular taxes on wealth \\
\hline & & & Regular inter-household cash transfer paid \\
\hline & & & Tax on income and social insurance contributions \\
\hline
\end{tabular}

Note: Sources entering extended income definition are in bold.

\footnotetext{
${ }^{4}$ A residual component is included in order to ensure consistency between aggregate income (whether gross or net) and individual income sources. Importantly, the residual component represents the part of income which is not accounted for by the available income decomposition sources in the EU-SILC. While we take the residual into account for the sake of consistency and transparency of the results, we did some robustness checks to show that this residual is irrelevant in the income decomposition exercise for most countries. This check is not reported here for sake of brevity. The results are however available upon request from the authors. For a technical discussion see Annex 2.

${ }^{5}$ See EU-SILC User Guide.
} 
In addition, and given the availability of new income components, the analysis focuses on an extended income definition. The rationale behind referring to a wider definition of income is that of accounting for additional income sources which may have played a non-negligible role in households' balances, particularly during the last cycle. The additional income sources relevant to this extension are (i) pensions received from individual private plans (other than those covered under the European System of integrated Social Protection Statistics - ESSPROS) and (ii) interests paid on mortgages, treated here as negative income source. Further details about the extended income definition are provided in Table l. In our analysis, the component of interests on mortgage is intentionally kept separate from other income sources, in order to highlight the effect of mortgages on private sector's leveraging in some countries.

\section{Standard indicators of inequality}

By looking at the standard array of inequality indicators adopted in the literature, the evolution of the Gini index over time (Figure 1) shows that, since the crisis, inequality initially declined in some countries. In most cases, inequality started rising again during the period of analysis, well above (as in the case of Spain and Ireland) or very close (e.g., in Greece and Italy) to the levels observed before the start of the crisis. The case of France stands alone, with inequality systematically increasing over the entire sample. The opposite dynamics are recorded in Germany and the Netherlands, with inequality overall trending lower starting from 2008. The after-crisis picture of inequality remained broadly stable in all other countries.

Figure 1 - GINI Index - after-tax (OECD-equivalent) income

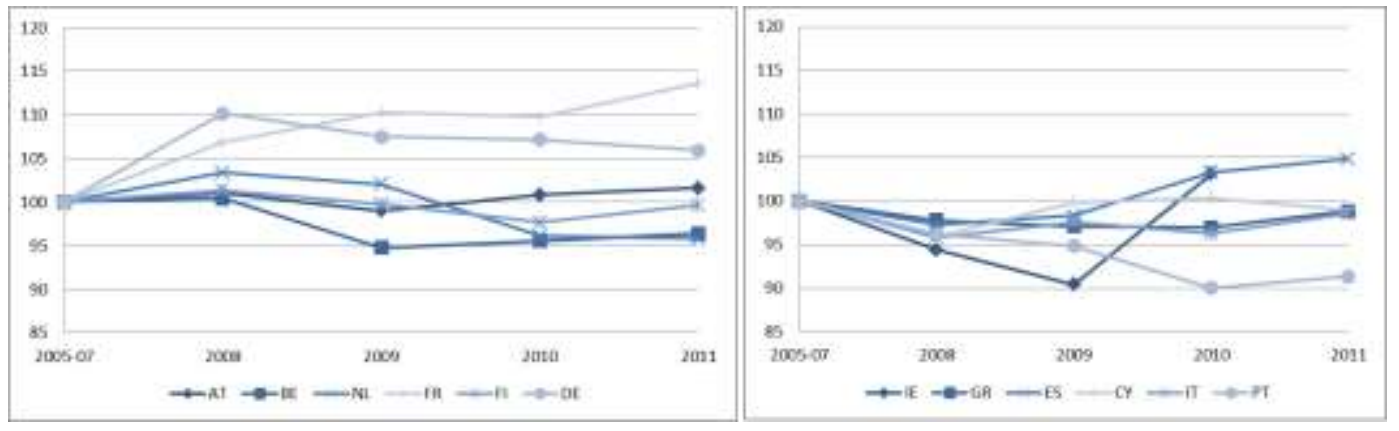

Note: Countries are clustered according to "program and vulnerable countries" (Cyprus (CY), Spain (ES), Greece (GR), Ireland (IE), Italy (IT), Portugal (PT)), and "northern countries" (Austria (AT), Belgium (BE), Germany (DE), Finland (FI), France (FR), the Netherlands (NL)). Where data are available, the evolution of inequality is presented normalized onto pre-crisis averages $(2005-07=100)$.

Figure 2 - p90/pl0 ratio - after-tax (OECD-equivalent) income
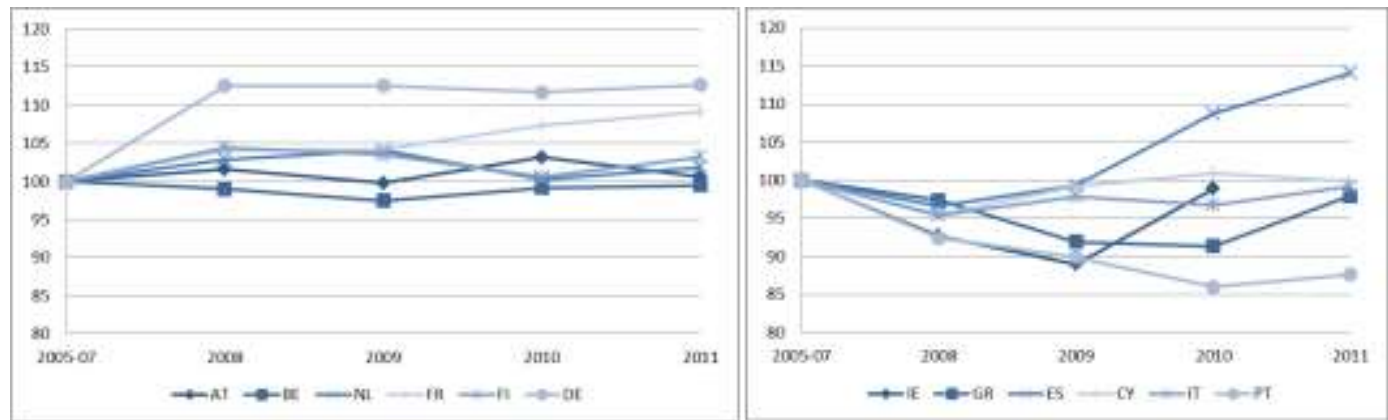

Note: Countries are clustered according to "program and vulnerable countries" (Cyprus (CY), Spain (ES), Greece (GR), Ireland (IE), Italy (IT), Portugal (PT)), and "northern countries" (Austria (AT), Belgium (BE), Germany (DE), Finland 
(FI), France (FR), the Netherlands (NL)). Where data are available, the evolution of inequality is presented normalized onto pre-crisis averages (2005-07=100).

The evolution of the income ratio of the richest and the poorest $10 \%$ of the population provides a broadly similar picture (Figure 2), with some notable exceptions. It should be noted, in first place, that the same evolution of the quantile ratio masks rather different dynamics across countries, with potentially different policy implications. For instance, the strong increase of the ratio in Spain reflects both a noticeable worsening in the lowest tail of the distribution as well as a significant increase of the income level of the richest (not reported here for sake of brevity). This is, for instance, different in France, where the observed dynamics results from an improvement in both segments of the population, with the richest moving towards relatively higher levels of income. While not accurate, a quick inspection suggests that looking at the extent of inequality among specific income quantiles may provide useful (and more in-depth) information about the homogeneity of different income strata in the population; thus, being a crucial element to consider when looking at the effect of policy interventions. Further, the analysis above seems to suggest the information provided by the quantile ratios not to be always consistent with that provided by a synthetic indicator such as the Gini index. In particular, by looking - again - at the case of Spain, the Gini index would show a mild increase in inequality in 2010-11 ( $+5 \%)$, while the ratio between the number of households in the top and the bottom quantiles increased three times as much over the same period, well above the value observed before the crisis. Yet again, while quantile ratios are very synthetic and ignore information on incomes in the middle of the distribution - nor they use information about the income distribution within the top and bottom quantiles - these developments are enough to conclude that the tails of the distribution play a relevant role; in which case the Gini index may not provide a reliable picture (see Section 4).

Table 2 - GINI Index - before- and after-tax (OECD-equivalent) income variables

\begin{tabular}{cccccccc}
\hline & \multicolumn{3}{c}{$\begin{array}{c}\text { Gross income } \\
\text { (extended definition) }\end{array}$} & & \multicolumn{3}{c}{$\begin{array}{c}\text { Disposable income } \\
\text { (extended definition) }\end{array}$} \\
\hline PT & 2007 & 2011 & first diff. & & 2007 & 2011 & first diff. \\
IE & 31.8 & 39.1 & -2.7 & PT & 37.3 & 34.8 & -2.5 \\
GR & 36.1 & 37.9 & 1.9 & ES & 31.4 & 33.2 & 1.8 \\
\hline IT & 35.8 & 35.8 & -1.8 & GR & 33.6 & 33.0 & -0.5 \\
ES & 33.7 & 35.0 & 1.3 & IE & 31.0 & 32.8 & 1.9 \\
FR & 29.7 & 33.7 & 4.0 & IT & 31.9 & 31.7 & -0.1 \\
DE & 33.6 & 33.2 & -0.4 & FR & 26.6 & 31.0 & 4.4 \\
\hline EA average & 33.0 & 32.8 & -0.2 & DE & 29.6 & 29.0 & -0.5 \\
BE & 31.3 & 31.3 & 0.0 & AT & 26.4 & 26.4 & 0.1 \\
\hline AT & 30.6 & 31.0 & 0.5 & FI & 26.1 & 26.3 & 0.1 \\
\hline FI & 30.7 & 30.3 & -0.4 & BE & 26.1 & 26.1 & 0.0 \\
NL & 32.0 & 30.0 & -2.0 & NL & 27.0 & 25.1 & -1.8 \\
\hline
\end{tabular}

Note: The euro area countries considered are (in alphabetical order) Austria (AT), Belgium (BE), Cyprus (CY), Germany (DE), Spain (ES), Finland (FI), France (FR), Greece (GR), Ireland (IE), Italy (IT), the Netherlands (NL), Portugal (PT). Countries are ranked in descending order according to Gini inequality index as measured in the latest available year (2011, 2010 in case of IE). 
Table 2 finally shows the Gini coefficient computed on the gross and disposable extended incomes (both equivalized), as defined previously, over the periods 2007 and 2011 (2010 in the case of Ireland). Importantly, countries are ranked in descending order according to inequality indexes as measured in the latest available year.

Not surprisingly, the level of inequality in all countries is lower when after-tax income is taken into account. Interestingly, however, countries' relative position somewhat changes depending on whether their rank is based on gross or net income. Among euro area countries, Spain appears as the country with the second highest level of inequality when looking at disposable income; being further away from the euro area average with respect to the gross income ranking. The opposite holds for countries like Austria and Belgium, where redistribution policies seem to have significantly lowered the degree of inequality compared to the euro area average. ${ }^{6}$ Putting all different pieces together, inequality developments are more complex than what a synthetic indicator can capture. Hence, a more granular analysis may add up to our understanding of such complexity. This is the purpose of our next sections.

\section{Methodology}

In order to analyze the dynamics of the contribution of each income source to the overall inequality, we outline two different inequality indexes and their decompositions by income sources: the Gini and the Zenga index. We will show that, while the decomposition of both indexes provide insightful information on the inequality dynamics by income sources, the Zenga (2007) index presents the additional advantage of allowing to quantify the role of population subgroups, hence 'zooming-in' on the distribution of income before and during the crisis. Importantly, since our analysis is concerned with distributional issues, and given the great importance proportional tax, inter-households transfer and contribution to social security play for inequality, the remainder of the analysis focuses on disposable income only. ${ }^{7}$

\subsection{Measuring inequality: a comparison}

The Gini index is, probably, the most used and well-known index in the literature on income inequality (see Gini, 1914), and its specifications are several (see Yitzhaki, 1997). As anticipated before, however, the Gini index often fails to take into account the effective impact of the right tail of the income distribution (i.e. the richest) with respect to the left part of the tail (i.e. the poorest). As we showed in the previous section, quantile ratios represent a way to capture the fundamental idea that the concepts of poor and rich are relative to each other. In order to cope with this problem along all the possible fractions of lowest (highest) incomes in the distribution, Zenga (2007) more recently proposed an inequality index based on the ratio between lower and upper arithmetic means. While we are not necessarily interested in introducing the Zenga index in itself, we are interested in its empirical application, especially with a view to measure inequality in relative terms, compared to a standard index such as Gini. In this setting, the assessment of inequality in the population is determined by the comparison of population sub-groups. The Gini index compares the left tail of the income distribution (the poorest) with the whole population by attributing a weight proportional to the population share. On the contrary, the Zenga (2007) index compares each disjoint sub-group using the same weight for each comparison; hence allowing for a better comparison for each sub-group (including a better assessment of the right part of the income distribution, i.e. the richest).

More formally, let $i=(1, \ldots, N)$ be the households in the population and $s=(1, \ldots, \mathrm{S})$ be the possible sources of income. It is then possibile to define an income matrix $\mathbf{Y}$, such that the element

\footnotetext{
${ }^{6}$ While changes in public policies may be relevant in changing economic inequality, to assess idiosyncratic tax reforms and their re-distributive effects is beyond the scope of this analysis.

${ }^{7}$ The results for gross income are available upon request from the authors.
} 
$y_{i s}$ represents the income of household $i$ given source $s$. The variable $y_{i}=\sum_{s=1}^{S} y_{i s}$ thus represents the total income for household $i$. Moving to the income source dimension, we will further assume each column vector to represent the sources, and that total income is a random variable in a simple linear relationship. Let us denote total income as $Y$ and the single variables representing the income sources as $y_{s}$, then:

$$
Y=\sum_{s=1}^{S} y_{s}
$$

Without loss of generality, we will assume for the remainder of this section that total incomes are ordered such that $0 \leq y_{1} \leq y_{2} \leq \cdots \leq y_{i} \leq \cdots \leq y_{N}$ (with at least one strictly positive observation). Let the mean (total) income be denoted by $\mu_{Y}=1 / N \sum_{i=1}^{N} Y_{i}$ and the mean income for each income source denotes as $\mu_{y_{s}}=1 / N \sum_{i=1}^{N} Y_{i s}$. The decomposition by income sources proposed for both indexes is then derived by applying the linearity property of the covariance - for the Gini index and the arithmetic mean - for the Zenga index. As discussed earlier, the Gini index presents some limitation when it comes to the relationship between the left tail (the poorest) and the right tail (the richest) of the income distribution. In fact, it is computed by averaging, for each quantile of the distribution (cumulated fraction of household), the sum of incomes along the left tail (cumulated income for that quantile), and then comparing it to the mean income of the whole population. As such, the Gini index underestimates the effect of the very poor with respect to the whole population (and the very rich) and stresses comparison between sub-groups that are more similar.

We are interested instead in a measure that can capture the increasing distance between the richest and the poorest parts of the population. That is where the alternative Zenga index comes into play (see Zenga, 2007). The index works as follows: for each element (household income level) $i$, let $\bar{M}_{i}=\frac{1}{i} \sum_{j=1}^{i} Y_{j}$ be the lower mean for the income level $i$ (i.e. the mean of the sub-group poorer than $i$ ) and $\stackrel{+}{M}_{i}=\frac{1}{N-i} \sum_{j=i+1}^{N} Y_{j}$ be the upper mean for the income level $i$ (i.e. the mean of the subgroup richer than $i$ ). The point inequality for the income level $i$ is then defined as:

$$
I_{i}=\frac{\stackrel{+}{M_{i}-\bar{M}_{i}}}{\stackrel{+}{M_{i}}}=1-\frac{\bar{M}_{i}}{+}
$$

which captures the relative variation of the lower mean with respect to the upper mean. The overall inequality index $I$ is then computed by averaging $I_{i}$ over all observations:

$$
I=\frac{1}{N} \sum_{i=1}^{N} I_{i}=\frac{1}{N} \sum_{i=1}^{N} \frac{\stackrel{+}{M_{i}-\bar{M}_{i}}}{\stackrel{+}{M_{i}}}
$$

The properties of the curve $I_{i}$ have been studied in Zenga (2007) and Greselin et al. (2009). As mentioned previously, due to its construction, the Zenga index allows for a comparison between each possible disjoint subgroup in the distribution. The intuition is that an increase in income for the richest $(1-p)$ fraction of the population will have an effect on the value of the inequality curve for the fraction of the $p$ poorest. In the next section, we will show how the Zenga decomposition follows and how changes in the distribution of inequality by population sub-groups work.

\subsection{Inequality indexes decomposition}

Among the many ways to compute the Gini index, we refer to the geometric approach, based on the Lorenz curve $L(p)$, which computes the Gini coefficient $G_{Y}$ as follows: 


$$
\begin{aligned}
G_{Y} & =1-2 \int_{0}^{1} L(p) d p \stackrel{B . P .}{=} \\
& =2 \int_{0}^{1} p L^{\prime}(p) d p-1
\end{aligned}
$$

where the last integral has been computed integrating by parts. Given two random variables $X$ and $Z$, let:

$$
G \operatorname{Cov}(X, Z)=\operatorname{cov}\left(X, F_{Z}(Z)\right)
$$

be the so-called Gini covariance between $X$ and $Z$. The Gini covariance differs from the standard covariance in that it does not measure the degree of linearity between two variables, but the degree of monotonicity, making it suitable for capturing non-linear (yet monotonical) relationships. This formulation will allow to express the Gini coefficient in terms of covariance with its rankings.

After some algebra, it is possible to express the Gini index in terms of Gini covariance between the income variable $Y$ and its fractional rankings, expressed in terms of its distribution function $F_{Y}(y)=$ $P(Y \leq y)$, as follows:

$$
G_{Y}=\frac{2}{\mu_{Y}} \operatorname{cov}\left(Y, F_{Y}(y)\right)
$$

by considering the uniform random variable $F_{Y}(y)=p$. The simple linearity property for the covariance of two variables leads us to write:

$$
\begin{gathered}
G_{Y}=\frac{2}{\mu_{Y}} \sum_{S=1}^{S} y_{s} G \operatorname{Cov}\left(y_{S}, Y\right) \\
=\frac{2}{\mu_{Y}} \sum_{s=1}^{S} \operatorname{cov}\left(y_{s}, F_{Y}(y)\right)
\end{gathered}
$$

which represents the Gini coefficient in terms of the covariance of source $s$ with the fractional rankings of the total income. Normalizing by $G_{Y}$ gives the relative contribution of source $s$ to the global income inequality.

De Vergottini (1950) identified a relationship between Gini's mean difference and the covariance. This concept is at the basis of the decomposition proposed by Lerman and Yitzhaki (1984; 1985). The latter authors show how the Gini coefficient can be rewritten by multiplying and dividing each income component $s$ by the covariance between the same income component $y_{s}$ and its cumulative distribution function, and by further multiplying and diving it by $\mu_{y_{s}}$, as follows:

$$
\begin{gathered}
G_{Y}=\frac{2}{\mu_{Y}} \sum_{s=1}^{s} \frac{\operatorname{cov}\left(y_{s}, F(Y)\right)}{\operatorname{cov}\left(y_{s}, F_{y_{s}}\right)} \frac{2 \operatorname{cov}\left(y_{s}, F\left(y_{s}\right)\right)}{\mu_{Y_{s}}} \frac{\mu_{y_{s}}}{\mu_{Y}} \\
=\frac{2}{\mu_{Y}} \sum_{s=1}^{S} R_{y_{s}} G_{y_{s}} W_{y_{s}}
\end{gathered}
$$

Expression (3) is a useful way to present income inequality as the sum of the product of three quantities: $R_{y_{s}}$ being the Gini correlation between income source $y_{s}$ and the total income, $G_{y_{s}}$ being the Gini index for the income component $y_{s}$, and $W_{y_{s}}$ being the share of total income due to income component $y_{s}$. While this Gini representation is standard, it is nonetheless necessary to 
understand comparisons with the alternative indicator employed (the Zenga index; see Zenga, 2007) and how the latter add up to a more-comprehensive analysis of inequality.

Zenga et al. (2012) proposed a point decomposition by sources which exploits the simple linearity property of the arithmetic mean of the distribution: the arithmetic mean of a linear combination of variables is the same linear combination of the arithmetic means of each variable. In other words, we can rewrite the lower and upper means of the distribution appearing in (1) and (2), as follows:

$$
\begin{gathered}
\bar{M}_{i}=\frac{1}{i} \sum_{j=1}^{i} \sum_{s=1}^{s} y_{j s}=\sum_{s=1}^{s} \sum_{j=1}^{i} \frac{1}{i} y_{j s}=\sum_{s=1}^{s} \bar{M}_{i s} \\
\stackrel{+}{M}_{i}=\frac{1}{N-i} \sum_{j=i+1}^{N} \sum_{s=1}^{s} y_{j s}=\sum_{s=1}^{s} \sum_{j=i+1}^{N} \frac{1}{N-i} y_{j s}=\sum_{s=1}^{s} \stackrel{+}{M}_{i s}
\end{gathered}
$$

Where $\stackrel{+}{M}_{i s}$ and $\stackrel{+}{M}_{i s}$ are, respectively, the upper and lower means for income group $i$ with respect to source $s$. In the light of the above, equation (2) is rewritten as:

$$
\begin{aligned}
& I=\frac{1}{N} \sum_{i=1}^{N} I_{i}=\frac{1}{N} \sum_{i=1}^{N} \frac{\stackrel{+}{M}_{i}-\bar{M}_{i}}{\stackrel{+}{M}_{i}}= \\
& =\frac{1}{N} \sum_{S=1}^{S} \sum_{i=1}^{N} \frac{\stackrel{+}{M}_{i s}-\bar{M}_{i s}}{+}=\frac{1}{N} \sum_{i}^{S} I_{S}
\end{aligned}
$$

where $I_{s}=\sum_{i=1}^{N} \frac{\stackrel{+}{M_{i s}}-\bar{M}_{i s}}{\stackrel{+}{M}_{i}}$ is the contribution of income source $s$ to global inequality. It is then possible to compute the relative contribution of each source to global inequality by writing: $\beta_{s}=\frac{I_{S}}{I}$ (with $\sum_{s} I_{s}=1$ ). In the same vein, an inequality index can be computed for different segments of the population, by exploiting the linear representation of the Zenga index (see Radaelli, 2010).

\subsection{Sample correction weights}

When dealing with the estimation of inequality indexes from survey-based data, it is important to take into account sample weights. For the Gini index, the fundamental problem is to correctly compute weight-based fractional rankings (see Van Kerm, 2009). On the contrary, and less trivially so, for the Zenga index we will need to introduce its computation in a frequency distribution framework (see also Zenga, 2007).

In particular, let $\left(y_{i}, w_{i}\right)_{i=1}^{N}$ be the representation of the $N$ observations with the respective sampling weights and let $0 \neq y_{1}^{*}, \ldots, y_{K}, \ldots, y_{K}^{*}$ (with $K \leq N$ ) be the unique observations of $\left(y_{i}\right)_{i=1}^{N}$. In order to compute the new fractional rankings, associated with the $K$ unique values, tied values must be considered (see Van Kerm, 2009). Once fractional rankings are computed, they can be directly used in Equation (3).

Let $n_{h}$ be the frequencies associated to each unique observation $y_{h}^{*}$, where $\sum_{h} n_{h}=n$, with $n$ being the total number of observation (e.g. the total number of inhabitants of a country) or, in other terms, $n=\sum_{i} w_{i}=\sum_{h} n_{h}$. Let $N_{h}=\sum_{t=1}^{h} n_{t}$ be the cumulative frequencies and $p_{h}=\frac{N_{h}}{n}$ be the cumulative relative frequencies. We can now define the low and upper means with respect to the 
cumulative relative frequencies $p_{h}: \quad \bar{M}_{p_{h}}=\frac{1}{N_{h}} \sum_{t=1}^{h} y_{t}^{*} n_{t} \quad$ and $\stackrel{+}{M_{p_{h}}}=\frac{1}{n-N_{h}} \sum_{t=h+1}^{K} y_{t}^{*} n_{t}$. Analogously to Equation (1), the point inequality index for level $p_{h}$ is then given by:

$$
I_{p_{h}}=\frac{\stackrel{+}{M}_{p_{h}}-\bar{M}_{p_{h}}}{\stackrel{+}{M} p_{h}}
$$

whereas the synthetic index is:

$$
I=\frac{1}{n} \sum_{h=1}^{K} I_{p_{h}} n_{h}
$$

Equation (6) is a weighted average of the point inequality indexes where weights are computed from the sampling weights. The latter computation is performed as follows:

$$
n_{h}=\sum_{i=1}^{N} w_{i} 1\left\{y_{h}^{*}=y_{i}\right\} \Leftrightarrow p_{h}=\frac{1}{\sum_{i} w_{i}} \sum_{i=1}^{N} w_{i} 1\left\{y_{h}^{*}=y_{i}\right\}
$$

where $\mathrm{l}\{\cdot\}$ is an indicator function which takes the value of 1 whenever $y_{h}^{*}=y_{i}$.

\section{Results}

In this section we look at the extent of inequality across countries and over time based on the two inequality measures set out above. Particularly, we try to understand how alternative inequality measures, capturing with different receptivity deviations from equality in different parts of the distribution, fare in practice. In Section 5.2 the analysis focuses instead on the inequality of different income sources, following the decomposition set out in the previous Section.

\section{5.l A quick comparison between inequality indexes}

Figures 3 plots the aggregate income inequality constructed from the standard Gini coefficient, as well as the Zenga coefficient, normalized on pre-2008 periods, and based on our extended income definition. For sake of comparability, we leave in the same chart the Gini and Zenga indexes based on standard income definition, where pensions received from individual private plans and interest on mortgage do not appear (see Table 1). Having the pre-2008 period as a benchmark is the result of both judgment on the observed labor market slack in 2008 (i.e. labor markets reacted with some lag to the real economic downturn) and practical considerations (i.e. 2007 is the first available year for some countries). Moreover, we assume 2008 to be a sensible choice for survey data as it may take some time for individuals to gauge their reduced income availability at the household level especially in the light of real public social spending effectively growing as of 2008-09 (as a percentage of GDP) in many euro area countries (see OECD, 2012).

The two indexes produce qualitatively a similar picture, albeit normalizing the two indexes on (own) pre-2008 averages show a substantial scale difference. As stressed earlier, the Gini index may however underestimate comparisons between the very poor (left-tailed) and the whole population, while emphasizing comparisons which involve almost identical population subgroups. Against the backdrop of a fall in real GDP in 2009 (see OECD, 2012), inequality seemed to have increased in most countries, independently of which index is regarded. However, in some countries, such as Greece, Ireland, Italy and Portugal, the Zenga indicator has decreased less in pre2008 terms (=100) compared to Gini, suggesting that the rise of inequality since 2008 has not been as modest as previous studies would suggest. On the contrary, the Zenga index, vis-à-vis Gini, tends to be generally lower for Germany and France, whereas a clear picture does not emerge for Belgium, 
Cyprus, Finland and the Netherlands, as the two indexes cross each other at different points of the sample.

Moreover, compared to the baseline income definitions, we show that considering extended income variables does not generally change the scale of the evolution of Zenga and Gini inequality in most countries (Figure 3). However, somewhat different patterns are observed in Belgium, Spain, Finland, Greece, Portugal and the Netherlands. By construction of the two indexes, this implies that some of the new variables considered may favour one tail of the distribution more than the other, having an (un)equalizing effect on total income inequality. At this stage the interpretation of the results is certainly challenging and can be better dealt with an analysis of different income categories. However, it is intuitive to assert that such developments are likely to be observed when income components have important (un-)equalizing effects, especially decreasing (increasing) inequality between the lower end and the middle of the distribution.

Figure 3 - Zenga and Gini coefficients - net income vs. net extended income

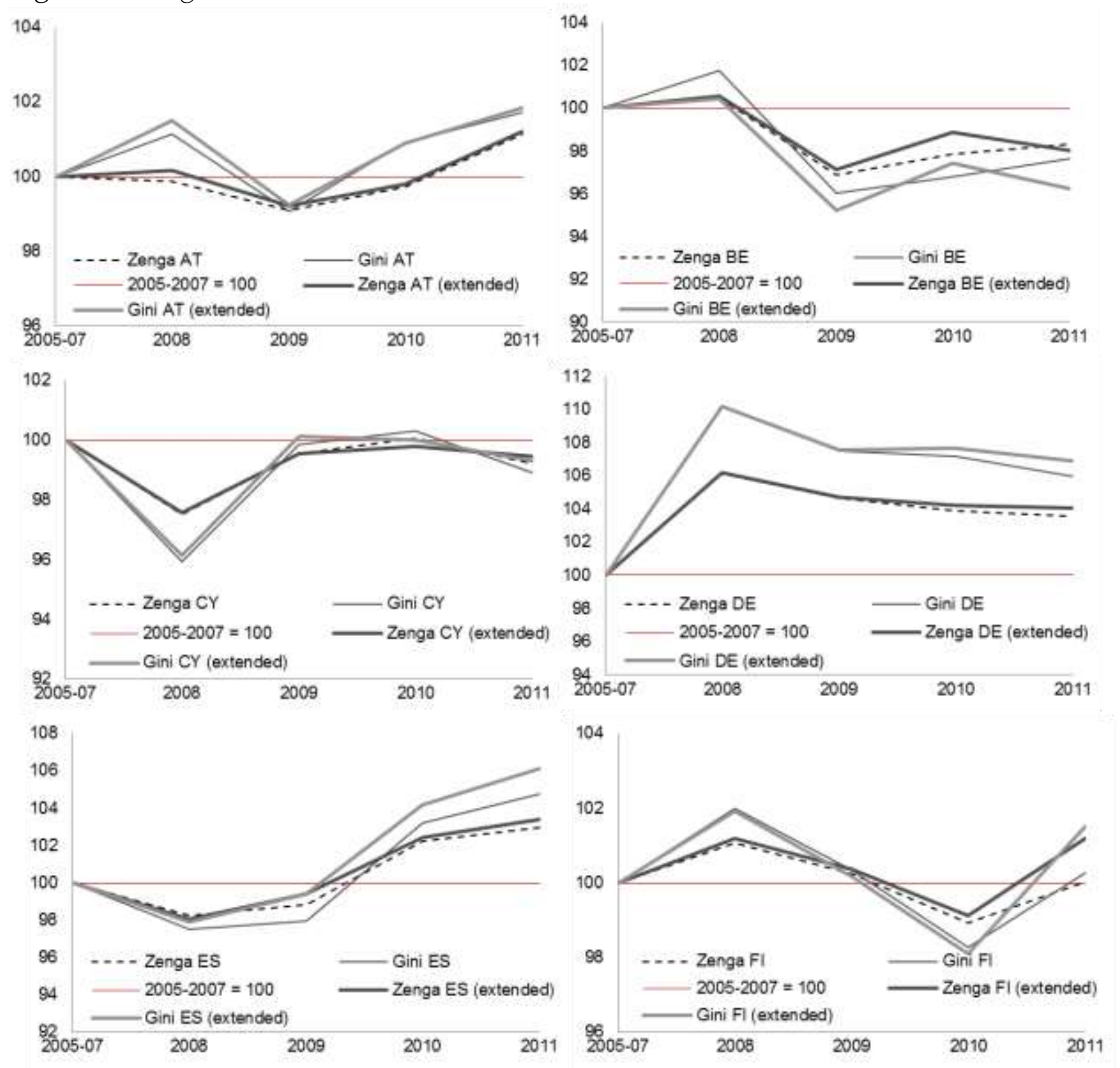

Note: The euro area countries considered are (in alphabetical order) Austria (AT), Belgium (BE), Cyprus (CY), Germany (DE), Spain (ES), Finland (FI), France (FR), Greece (GR), Ireland (IE), Italy (IT), the Netherlands (NL), Portugal (PT). Where data is available, the evolution of inequality is presented normalized onto pre-crisis averages $(2005-07=100)$. 
Figure 3 (continued) - Zenga and Gini coefficients - net income vs. net extended income

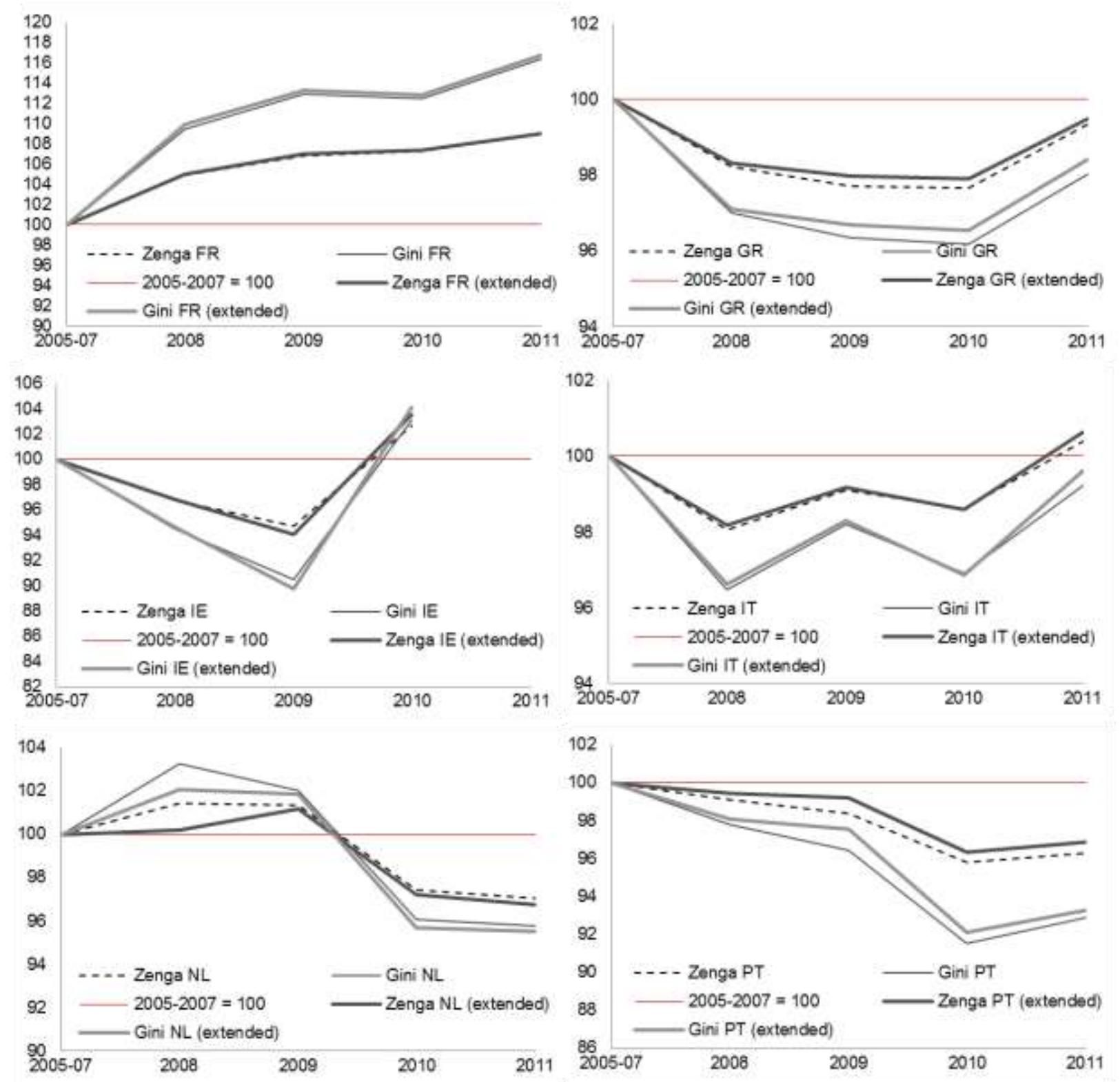

Note: The euro area countries considered are (in alphabetical order) Austria (AT), Belgium (BE), Cyprus (CY), Germany (DE), Spain (ES), Finland (FI), France (FR), Greece (GR), Ireland (IE), Italy (IT), the Netherlands (NL), Portugal (PT). Where data are available, the evolution of inequality is presented normalized onto pre-crisis averages (2005-07=100).

\subsection{Decomposition of inequality by income sources}

In order to get deeper into the drivers of the inequality developments discussed above, we quantify the extent to which total income inequality (measured by the Zenga index) is explained by single income sources (Table 3); see Zenga et al. (2012). ${ }^{8}$ It emerges that, between 2008 and 2010, the (positive) contribution of income from employment to overall inequality declined in all countries except in Ireland and, to a lesser extent, in Cyprus and Finland. Although less sizeable compared to dependent employment, the contribution from self-employment also declined in all countries (except Austria). At the same time, however, the share on total income of payment for direct taxes remained high while the share of interests on mortgage has been quantitatively smaller (i.e. again,

\footnotetext{
${ }^{8}$ For a discussion see Annex 2.
} 
taxes and interests on mortgages are treated as negative income sources). Further, the contributions of the latter two declined over time.

Clearly, if an income source represents a large share on total income (and this varies over time), it may have - in principle - a strong effect on inequality. However, the extent to which this is likely to affect inequality as a whole depends on the equality of the individual source itself. We start by looking at the pre-crisis (2005-2007). Total inequality is explained in order of importance by labour income, income from self-employment, other income, cash transfer (with the exceptions of France, Greece, Italy and Portugal, where cash transfers rank as third income source and, compared to the other countries, explains a much higher share of total inequality).

Table 3 - Contribution of income sources - net extended income (Zenga index=100)

\begin{tabular}{|c|c|c|c|c|c|c|}
\hline & & $2005-2007$ & 2008 & 2009 & 2010 & 2011 \\
\hline \multirow[t]{7}{*}{ AT } & Labour income & 98.8 & 110.4 & 106.4 & 112.7 & 105.4 \\
\hline & Self-empl. lab. income & 21.2 & 17.4 & 22.9 & 21.0 & 19.2 \\
\hline & Non-cash lab. income (ext) & 0.0 & 0.0 & 0.0 & 0.0 & 0.0 \\
\hline & Cash transfers & 21.2 & 16.9 & 15.5 & 12.7 & 17.0 \\
\hline & Other income (ext) & 6.3 & 9.5 & 7.2 & 8.8 & 10.1 \\
\hline & Interests on mortg. & -0.4 & -0.6 & -0.6 & -0.6 & -0.7 \\
\hline & Taxes & -47.4 & -53.6 & -51.3 & -54.7 & -51.5 \\
\hline \multirow[t]{7}{*}{$\mathrm{BE}$} & Labour income & 128.7 & 118.7 & 125.9 & 122.3 & 129.4 \\
\hline & Self-empl. lab. income & 16.6 & 22.5 & 13.7 & 11.7 & 16.0 \\
\hline & Non-cash lab. income (ext) & 0.9 & 1.0 & 1.2 & 1.0 & 1.1 \\
\hline & Cash transfers & -4.4 & -3.9 & -1.2 & 0.7 & -4.7 \\
\hline & Other income (ext) & 12.8 & 9.3 & 9.7 & 12.9 & 9.0 \\
\hline & Interests on mortg. & -1.6 & -1.6 & -1.8 & -2.0 & -2.2 \\
\hline & Taxes & -52.9 & -45.9 & -47.5 & -46.7 & -49.5 \\
\hline \multirow[t]{7}{*}{ CY } & Labour income & 89.7 & 88.5 & 88.5 & 92.7 & 91.6 \\
\hline & Self-empl. lab. income & 12.6 & 15.3 & 13.0 & 12.4 & 11.0 \\
\hline & Non-cash lab. income (ext) & 0.4 & 0.3 & 0.3 & 0.3 & 0.3 \\
\hline & Cash transfers & 4.8 & 5.4 & 9.2 & 8.4 & 8.5 \\
\hline & Other income (ext) & 9.1 & 7.6 & 7.2 & 5.9 & 7.6 \\
\hline & Interests on mortg. & -0.4 & -1.1 & -1.2 & -1.2 & -1.1 \\
\hline & Taxes & -16.3 & -16.2 & -16.9 & -18.4 & -18.8 \\
\hline \multirow[t]{7}{*}{$\mathrm{DE}$} & Labour income & 101.5 & 101.7 & 107.8 & 110.5 & 109.7 \\
\hline & Self-empl. lab. income & 25.3 & 28.2 & 23.4 & 19.2 & 16.9 \\
\hline & Non-cash lab. income (ext) & 1.3 & 2.0 & 2.0 & 1.9 & 1.5 \\
\hline & Cash transfers & 5.3 & 4.9 & 4.2 & 6.5 & 8.5 \\
\hline & Other income (ext) & 8.2 & 8.2 & 7.3 & 11.0 & 9.6 \\
\hline & Interests on mortg. & -0.1 & 0.0 & 0.0 & -1.5 & -1.8 \\
\hline & Taxes & -41.7 & -45.0 & -44.6 & -47.7 & -45.7 \\
\hline \multirow[t]{3}{*}{ ES } & Labour income & 34.2 & 103.9 & 99.6 & 94.6 & 92.1 \\
\hline & Self-empl. lab. income & 2.5 & 7.4 & 7.6 & 10.8 & 11.7 \\
\hline & Non-cash lab. income (ext) & 0.2 & 1.1 & 0.8 & 0.7 & 0.4 \\
\hline
\end{tabular}




\begin{tabular}{|c|c|c|c|c|c|c|}
\hline & Cash transfers & 2.7 & 7.9 & 9.6 & 10.8 & 11.4 \\
\hline & Other income (ext) & 2.0 & 5.2 & 5.9 & 5.5 & 4.5 \\
\hline & Interests on mortg. & -0.2 & -1.1 & -0.8 & -0.9 & -0.6 \\
\hline & Taxes & -8.1 & -24.4 & -22.7 & -21.4 & -20.6 \\
\hline \multirow[t]{7}{*}{ FI } & Labour income & 125.8 & 121.2 & 125.1 & 123.5 & 115.5 \\
\hline & Self-empl. lab. income & 13.3 & 16.1 & 14.2 & 11.5 & 10.7 \\
\hline & Non-cash lab. income (ext) & 1.9 & 2.0 & 1.8 & 1.9 & 1.6 \\
\hline & Cash transfers & -7.8 & -6.3 & -6.4 & -4.5 & -3.5 \\
\hline & Other income (ext) & 25.7 & 22.3 & 21.6 & 20.4 & 22.3 \\
\hline & Interests on mortg. & -1.8 & -2.7 & -2.7 & -2.0 & -1.3 \\
\hline & Taxes & -57.2 & -52.5 & -53.5 & -50.9 & -48.6 \\
\hline \multirow[t]{7}{*}{ FR } & Labour income & 92.1 & 67.1 & 68.8 & 69.8 & 70.3 \\
\hline & Self-empl. lab. income & 17.9 & 15.7 & 15.2 & 13.0 & 13.6 \\
\hline & Non-cash lab. income (ext) & 0.0 & 0.0 & 0.0 & 0.0 & 0.0 \\
\hline & Cash transfers & 20.0 & 19.2 & 15.8 & 19.4 & 18.3 \\
\hline & Other income (ext) & 8.7 & 30.7 & 31.9 & 28.6 & 30.2 \\
\hline & Interests on mortg. & -1.0 & -0.5 & -0.7 & -0.7 & -0.6 \\
\hline & Taxes & -37.7 & -29.0 & -31.0 & -30.0 & -31.8 \\
\hline \multirow[t]{7}{*}{ GR } & Labour income & 79.5 & 83.6 & 77.3 & 72.1 & 72.7 \\
\hline & Self-empl. lab. income & 42.8 & 38.9 & 40.2 & 42.9 & 41.7 \\
\hline & Non-cash lab. income (ext) & 0.3 & 0.3 & 0.2 & 0.3 & 0.2 \\
\hline & Cash transfers & 16.0 & 16.1 & 17.3 & 19.0 & 17.7 \\
\hline & Other income (ext) & 9.5 & 8.5 & 8.2 & 9.1 & 8.4 \\
\hline & Interests on mortg. & -0.7 & -0.7 & -0.4 & -0.4 & -0.5 \\
\hline & Taxes & -47.3 & -46.7 & -42.9 & -42.9 & -40.2 \\
\hline \multirow[t]{7}{*}{ IE } & Labour income & 101.7 & 105.1 & 114.2 & 106.8 & . \\
\hline & Self-empl. lab. income & 32.7 & 25.7 & 22.9 & 14.7 & . \\
\hline & Non-cash lab. income (ext) & 0.7 & 0.7 & 0.4 & 0.4 & . \\
\hline & Cash transfers & -4.2 & -2.7 & -0.5 & 8.6 & . \\
\hline & Other income (ext) & 6.3 & 9.2 & 5.3 & 4.3 & . \\
\hline & Interests on mortg. & -2.1 & -2.6 & -3.5 & -2.2 & . \\
\hline & Taxes & -35.1 & -35.5 & -38.9 & -32.5 & . \\
\hline \multirow[t]{7}{*}{ IT } & Labour income & 73.4 & 68.6 & 68.1 & 68.3 & 68.1 \\
\hline & Self-empl. lab. income & 41.6 & 47.8 & 43.4 & 45.4 & 41.5 \\
\hline & Non-cash lab. income (ext) & 0.2 & 0.3 & 0.3 & 0.3 & 0.2 \\
\hline & Cash transfers & 23.1 & 25.7 & 27.8 & 27.5 & 28.9 \\
\hline & Other income (ext) & 6.4 & 7.4 & 7.5 & 6.5 & 8.0 \\
\hline & Interests on mortg. & -0.6 & -0.4 & -0.4 & -0.5 & -0.5 \\
\hline & Taxes & -44.2 & -49.3 & -46.8 & -47.6 & -47.2 \\
\hline \multirow[t]{2}{*}{ NL } & Labour income & 118.0 & 117.0 & 113.9 & 122.9 & 124.1 \\
\hline & Self-empl. lab. income & 19.4 & 27.4 & 30.0 & 28.0 & 28.5 \\
\hline
\end{tabular}




\begin{tabular}{|c|c|c|c|c|c|c|}
\hline & Non-cash lab. income (ext) & 2.3 & 2.6 & 2.7 & 2.3 & 2.1 \\
\hline & Cash transfers & 14.3 & 11.3 & 14.3 & 14.3 & 14.0 \\
\hline & Other income (ext) & 13.1 & 21.1 & 18.7 & 11.2 & 12.5 \\
\hline & Interests on mortg. & -3.0 & -6.9 & -5.6 & -5.1 & -5.0 \\
\hline & Taxes & -64.0 & -72.4 & -74.0 & -73.7 & -77.3 \\
\hline \multirow[t]{7}{*}{ PT } & Labour income & 101.2 & 94.9 & 94.3 & 102.4 & 101.1 \\
\hline & Self-empl. lab. income & 15.9 & 20.5 & 19.9 & 11.9 & 11.5 \\
\hline & Non-cash lab. income (ext) & 1.0 & 0.0 & 0.0 & 0.2 & 0.3 \\
\hline & Cash transfers & 21.4 & 20.5 & 19.4 & 19.2 & 21.9 \\
\hline & Other income (ext) & 3.2 & 3.6 & 4.1 & 5.3 & 4.4 \\
\hline & Interests on mortg. & -1.3 & -1.3 & -1.1 & -1.3 & -0.6 \\
\hline & Taxes & -41.4 & -38.2 & -36.7 & -37.9 & -39.1 \\
\hline
\end{tabular}

Note: The euro area countries considered are (in alphabetical order) Austria (AT), Belgium (BE), Cyprus (CY), Germany (DE), Spain (ES), Finland (FI), France (FR), Greece (GR), Ireland (IE), Italy (IT), the Netherlands (NL), Portugal (PT). Contribution of single income sources normalized onto overall inequality (Zenga index = 100).

At the start of the crisis (2008, compared to pre-crisis) a strong increase of inequality explained by labour income in Spain and Austria is observed; together with strong reductions in the contribution of labour income in France and increases in the contribution of other income to overall inequality. After 2008, the contribution of labour income decreased in Spain and Greece and it increased in Belgium and the Netherlands. At the same time, the contribution of self-employment labour income to overall inequality decreased in Germany. These results appear very much in line with the decomposition by sources of the Gini index (see Annex 1 - Table 2A).

In the light of the considerations above, the effect of individual income sources on overall inequality will also depend on which point of the distribution this (extra) source is earned. In other words, it may be important to assess the marginal effect of both standard and extra income sources on overall inequality measures. In this respect, following our previous discussion in Section 4.2 (equation 3), the Gini decomposition allows to measure to what extent the observed contributions depend on: how (un)equal the distribution of each income source is $\left(G_{y s}\right)$; the relative importance of each individual component as a share of total income $\left(W_{y s}\right)$; the correlation between the distribution of aggregate income and that of the individual income component $\left(R_{y s}\right)$; allowing to calculate marginal effects. Marginal effects here account for the percentage change in inequality resulting from a small percentage change in income from a given source, all other things being equal. This corresponds to the original contribution of each source to income inequality minus each source share on total income.

The results in Figure 4 show, for instance, that in a country like Spain, a 1\% increase in labour income contributed to an increase on the inequality computed on total income by about $0.24 \%$ in 2007. Labour income and - to a lesser extent - self-employment labour income and non-cash labour income have had a strong un-equalizing effect over time in most countries (except in France and Spain). An important un-equalising effect of income from self-employment is observed instead in Italy. Cash transfers and taxes consistently acted in favouring people at the lower end of the income distribution. Compared to the other income sources, results for the Netherlands show that interest on mortgages has had a relatively strong un-equalizing effect on total income. To a much lesser extent, a similar pattern is observed in France, Greece, Italy and Spain. In the case of Finland, France and the Netherlands, and, to a somewhat lesser extent, Austria, Belgium, Germany, Spain, Ireland, Italy and Greece other income sources (including private pension plans) have had an unequalizing effect. 
Figure 4 - Marginal effects

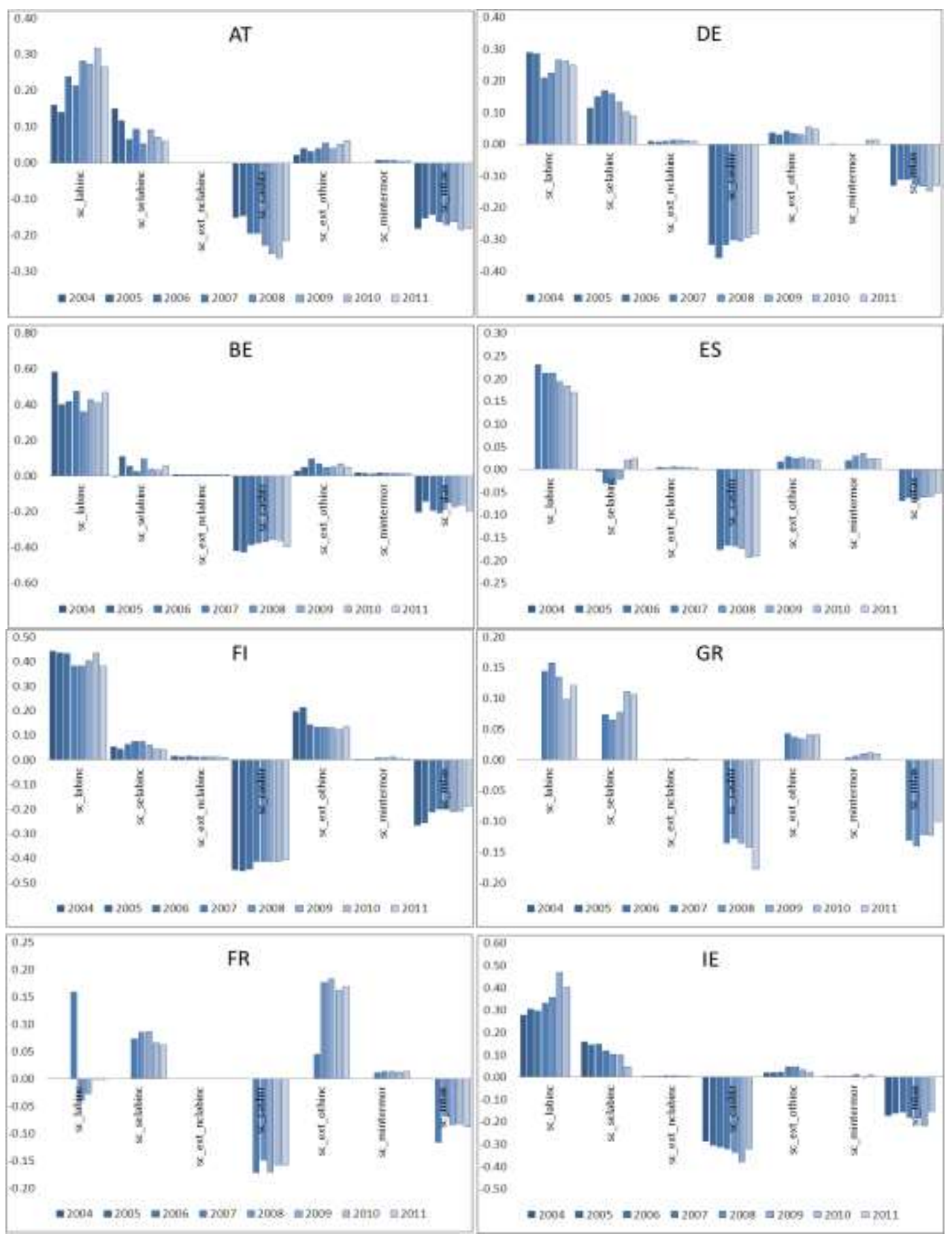




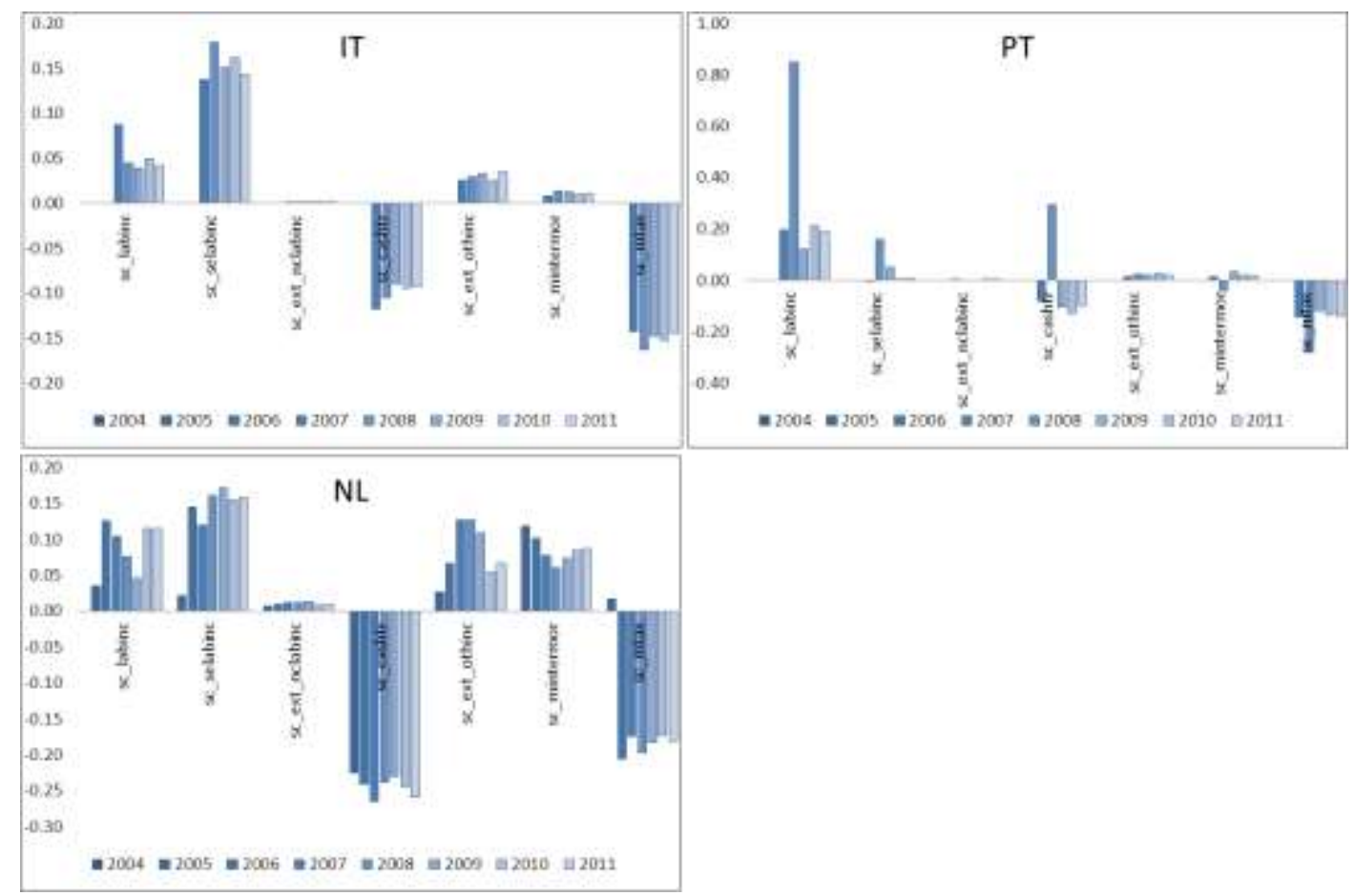

\subsection{Zooming-in: inequality decomposition by income quantiles}

The contribution of each source to the global inequality is related to specific income levels. In what follows, we take a closer look at the decomposition of inequality by source, by considering the mean contribution for a specific pair quantile-source. In particular, we compare how the relative contribution of each income source is distributed across quantiles in 2007 (Fig. 5, left-panels) and 2011 (Fig. 5, right panels).

Overall, in both 2007 and 201l, labour income seems to have played a relatively major role in the lowest percentiles $(20,40)$. This picture is different in Portugal (where labour income is high also in the top 80\%), Greece and Spain (broadly flat). In 2011, relative to 2007, these figures are confirmed for most countries again with the exceptions of Spain and Greece, where labour income is more heterogeneous across quantiles, Ireland, where labour income became relatively more important in the middle of the distribution, and Portugal, where the weight of labour income decreases towards the right tail. As far as "other income" is concerned important increases are observed in France in 2011, as also confirmed in the previous table with relative contributions. 
Figure 5 - Index decomposition by quantiles (based on Zenga)

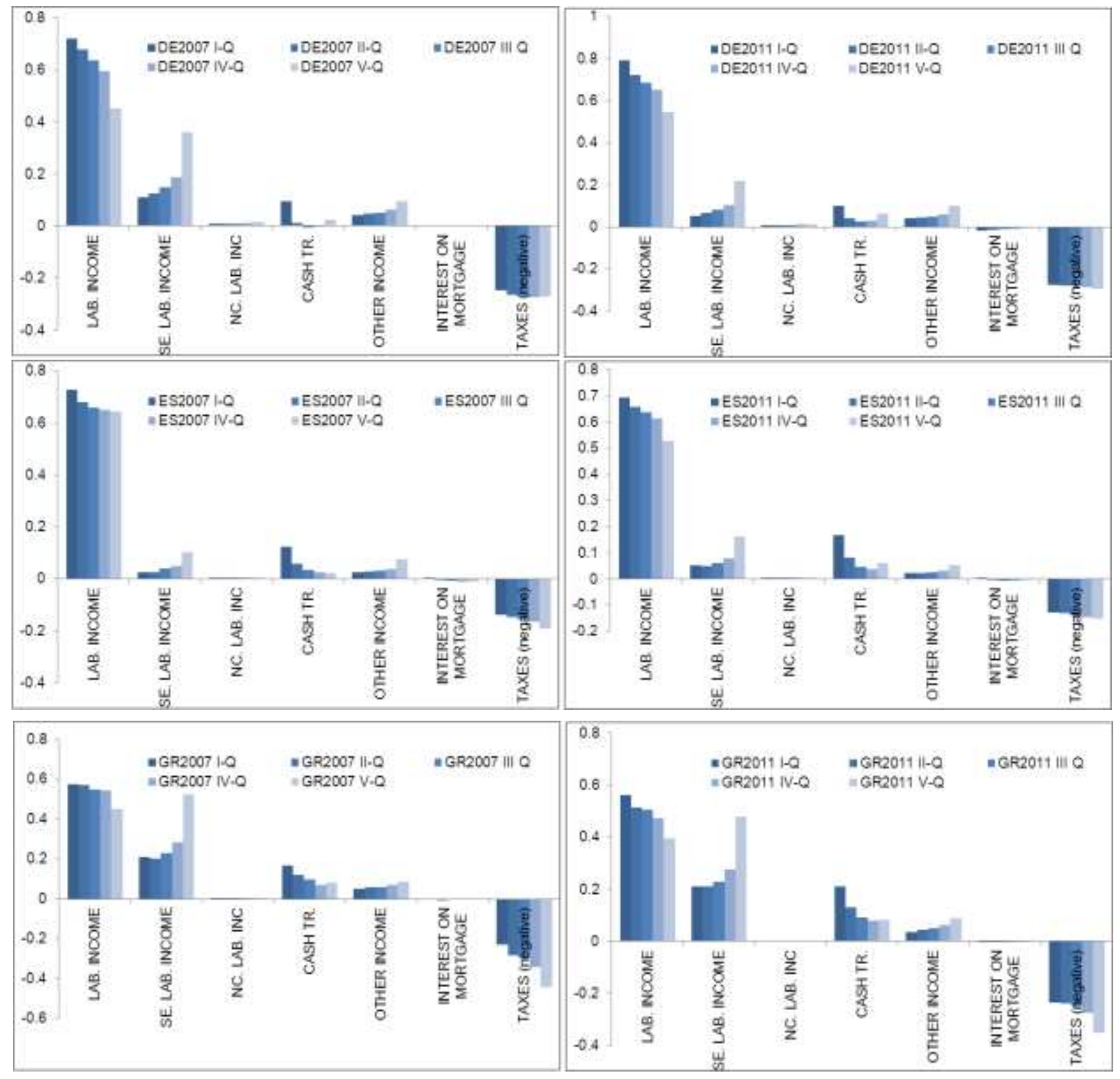




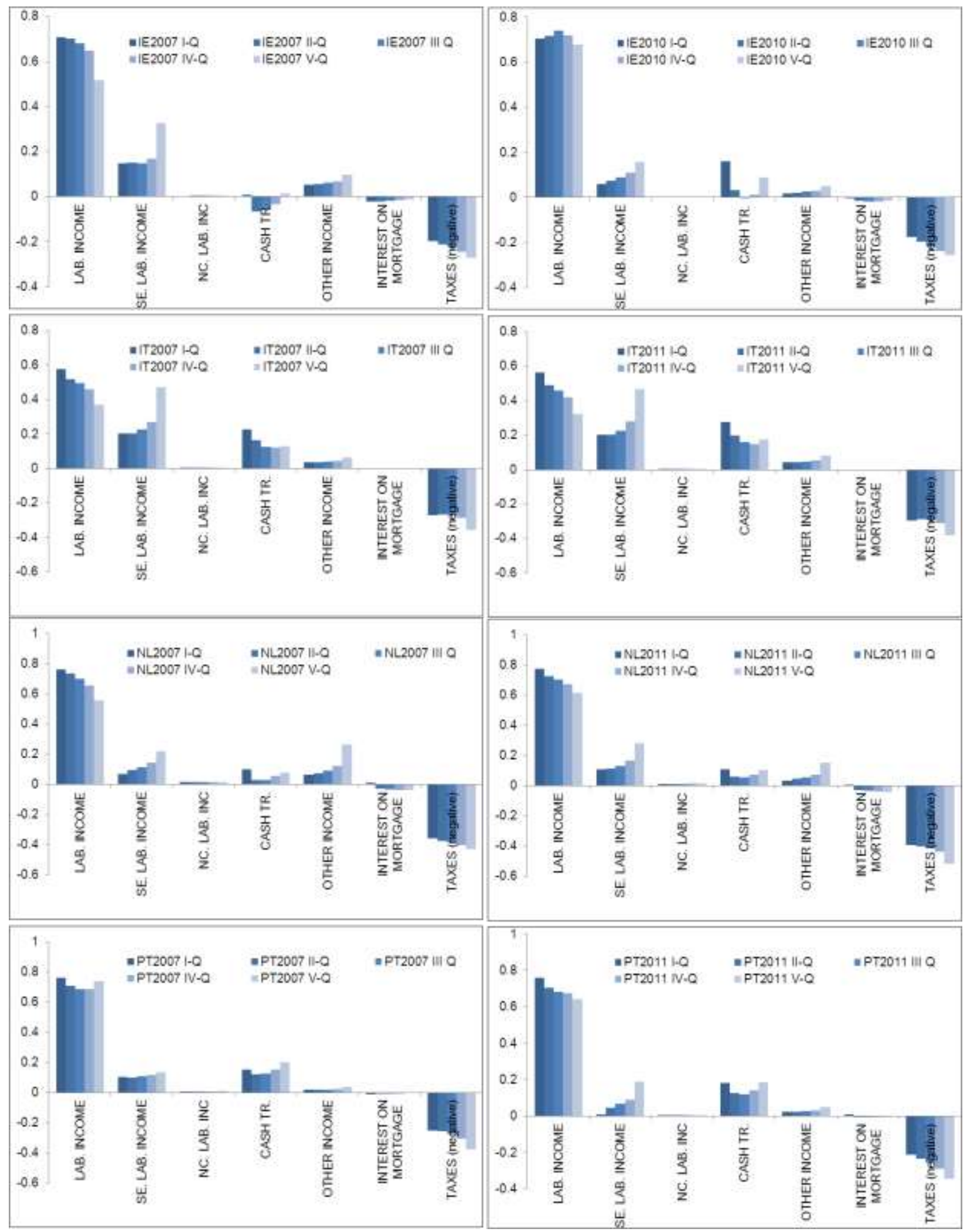

\subsection{Zooming-in: quantile regressions}

With the aim of providing a richer characterization of the data, allowing to consider the impact of (some) covariates on the entire distribution of household income (by quantiles), quantile regressions are finally run for each country (see Cameron and Trivedi, 2010; Chamberlain, 1994). The dependent variable is the (log) total household disposable income for the cross sections of 
2007 and 2011. As income observations are available at the household level, the exercise is performed by looking at the characteristics of a representative individual in each household (head). Information about the other individuals in the households is considered as well (number of children, head's partner working status). Importantly these estimates show the relationship between covariates and log total disposable income and do not necessarily represent a causal relationship. The analysis presented here allows digging into the determinants of income inequality, providing a unique country-by-country assessment of the drivers of inequality by households' head characteristics. Such an analysis goes beyond an income decomposition by source of the previous sections and rather looks at the significance of household head's characteristics in driving total (household) income (and, again, not its individual components) by quantiles.

In particular, the proposed approach allows estimating the effect of potential determinants of inequality on all parts of the income distribution. An analysis of this type is better suited to answer the question about what are the drivers of income inequality. In this exercise, the explanatory variables for each country include: Partner employed ( $=1$ if the head's partner is employed); Number of children (i.e. or the total number of people in the household minus the head and other adults); Parttime Job (=1 if the head has a part-time job); Age groups (=1 if the head is less than 24 years old, =2 if the head is between 25 and 39 years old, =3 if the head is between 40 and 54 years old, =4 if the head is between 55 and 75 years-olds); Housing tenure/tenure status (=1 if the head is a tenant but he/she does not pay rent (beneficiary), $=2$ if the head is owner of the dwelling, $=3$ if the head is owner of the dwelling but with a mortgage, $=4$ if the head is a tenant); Educational attainment (=1 if the head has low education, $=2$ if the head has medium education, $=3$ if the head has high education) ${ }^{9}$

In the analysis, which we limit to a visual inspection, we also plot the conditional mean of household disposable income based on a standard OLS regression - using the same set of covariates - to show that a more complete picture of covariate effects is provided by estimating a family of conditional quantile functions. The interpretation of quantile regression results is similar to that of OLS estimates, with the important difference that standard ordinary least square estimates only look at the effect of mean income on the overall income distribution.

In each quantile regression, the first category for each explanatory variable (e.g., low education in the case of educational attainment) is omitted, so that the coefficients may be interpreted relative to this omitted category. Again, the impact on income of the variables listed above is likely to differ across quantiles (e.g. higher education is arguably more valuable for high income households' heads than for low income ones). OLS ignore such heterogeneity as they only provide estimates of the mean effect of the covariates (see Cameron and Trivedi, 2010).

The Figure below (Figure 6) presents a summary of quantile regression results for some selected country examples. The analysis considers 10 covariates, plus an intercept. Again, the quantile regression focuses on the quantile of household income conditional on the household's head characteristics. For each of the 10 coefficients, we plot the 19 distinct quantile regression estimates with the quantile dimension ranging from 0.05 to 0.95 as the solid curve with filled dots. For each covariate, these point estimates are understood as a small change in household's head characteristics in each quantile of the overall distribution. Each of the plots has a horizontal quantile scale, and the vertical scale indicates the covariate effect.

The dashed line in each figure shows the ordinary least squares estimate of the conditional mean effect. The two dotted lines represent conventional 90 percent confidence intervals for the least squares estimate. The shaded grey area depicts a 90 percent pointwise confidence band for the quantile regression estimates. In the first panel of the figure, the intercept of the model may be interpreted as the estimated conditional quantile function of the household disposable income distribution of a family head whose partner is unemployed, himself/herself with a full-time job, less than 24 years old, who is a tenant not paying his/her rent and with low education.

\footnotetext{
${ }^{9}$ Based on ISCED classifications.
} 
We will confine our discussion to only a few of the covariates. At any chosen quantile we can ask, for example, how different is the corresponding impact on household disposable income, given its head characteristics. We start by interpreting the results for 2007 for Germany (DE), Spain (ES) and Italy (IT) (Figure 7).

Having a partner employed is relevant especially at the lower end of the distribution. In the picture, family heads to the left of the chart are those with low income. As it can be gauged from the second right panel in each Figure, the effect of having a partner employed is always positive, with a marginal higher effect for the I quantile. In this case, a downward sloping curve means that a l p.p. increase in the likelihood of having a partner employed for a family head increases income more at the bottom than at the top of the distribution. This effect is monotone in the case of Spain and Italy, but it is non-linear in the case of Germany. A high number of children has consistently a negative impact on household disposable income (controlling for other factors). In addition, having a head with a part-time job is always found to have a negative impact on household disposable income. However, the effect is particularly negative for smaller quantiles. Moreover, compared to a person less than 24 years old, being between the ages of 25-39, 40-54 or 55-75 does have an increasing positive impact of household disposable income, possibly because of the effect of tenure on wage. Within each age category, this effect is however downward sloping, with age being a more relevant factor at lower quantiles. Being the owner of the dwelling (tenure status $=2$ ) is moreover found to have a positive impact on household disposable income and this effect is found to decrease by quantiles. Finally, compared to a head with low education, having medium or high education is always found to have a positive effect on income, and this is found to increase every time by quantile groups (the richer the household the stronger the effect of education).

All in all, the homogeneity hypothesis for the 2007 regression results (or the hypothesis that quantile regression results are not statistically different from OLS estimates) is rejected in most cases, as evidenced by the fact that quantile regression estimates do not stand within the OLS estimated confidence bands. This provides an indirect test that going beyond a mean-regression approach is useful, validating a quantile regression approach.

When moving to the results for the 2011 cross-section, the results change quite dramatically and, albeit some patterns, as described previously, are preserved, the picture becomes much less clear (Figure 7). In particular, while quantiles are still non-linear, the homogeneity hypothesis is not rejected in most cases. On the contrary, quantile regression results show a more stable pattern of return across quantiles for many of the dummy variables considered, consistent, in this case, with OLS estimates. For the three countries under scrutiny, sometimes a big blip for bottom/top-income households is found, which only in a few cases is statistically different from linear regression estimates. These results suggest that the impact of each covariate on different parts of the income distribution has become more "flat" during the crisis. In other words, quantile dispersion, while significant in 2007, decreased in 2011, with differences across covariates (head's individual characteristics) becoming not significantly different across quantiles. This seems to suggest that the crisis has "smoothed" the effect of individual household (head's) characteristics, against other factors (i.e. possibly varying income source share and contribution over time). 
Figure 6 - Quantile regressions (2007) for selected EA countries

(i) Germany (DE)
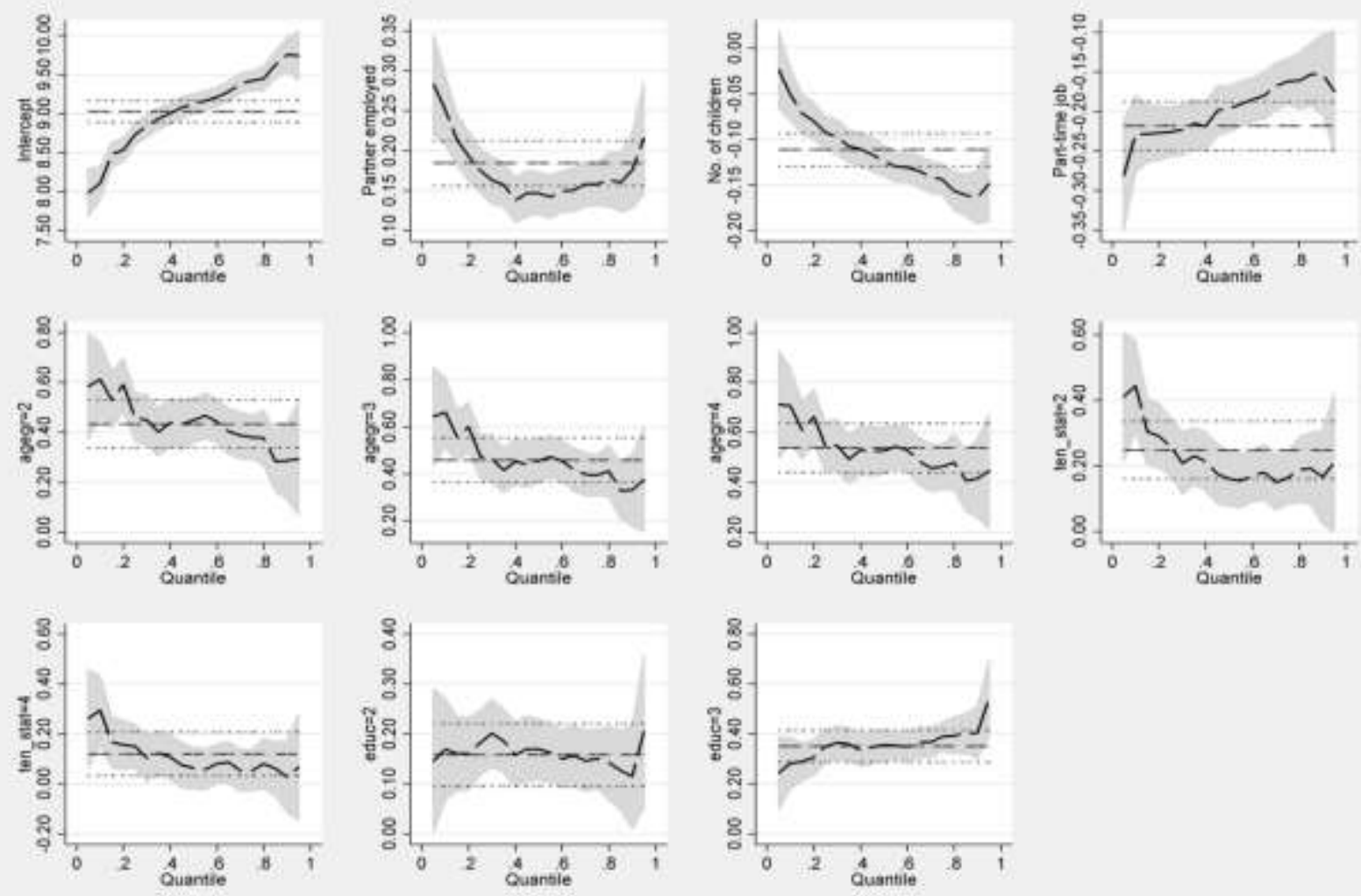

(ii) Spain (ES)
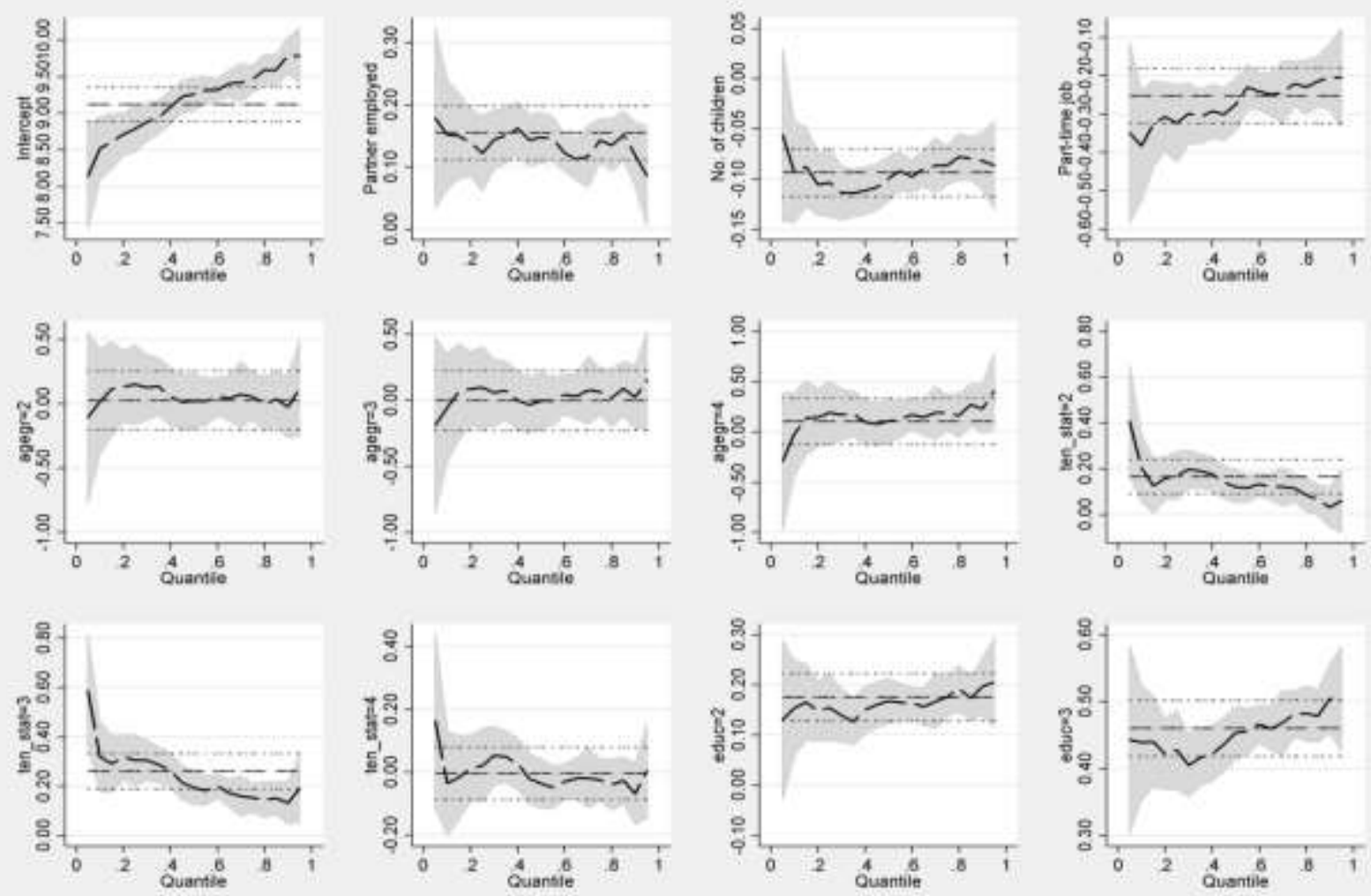
(iii) Italy (IT)
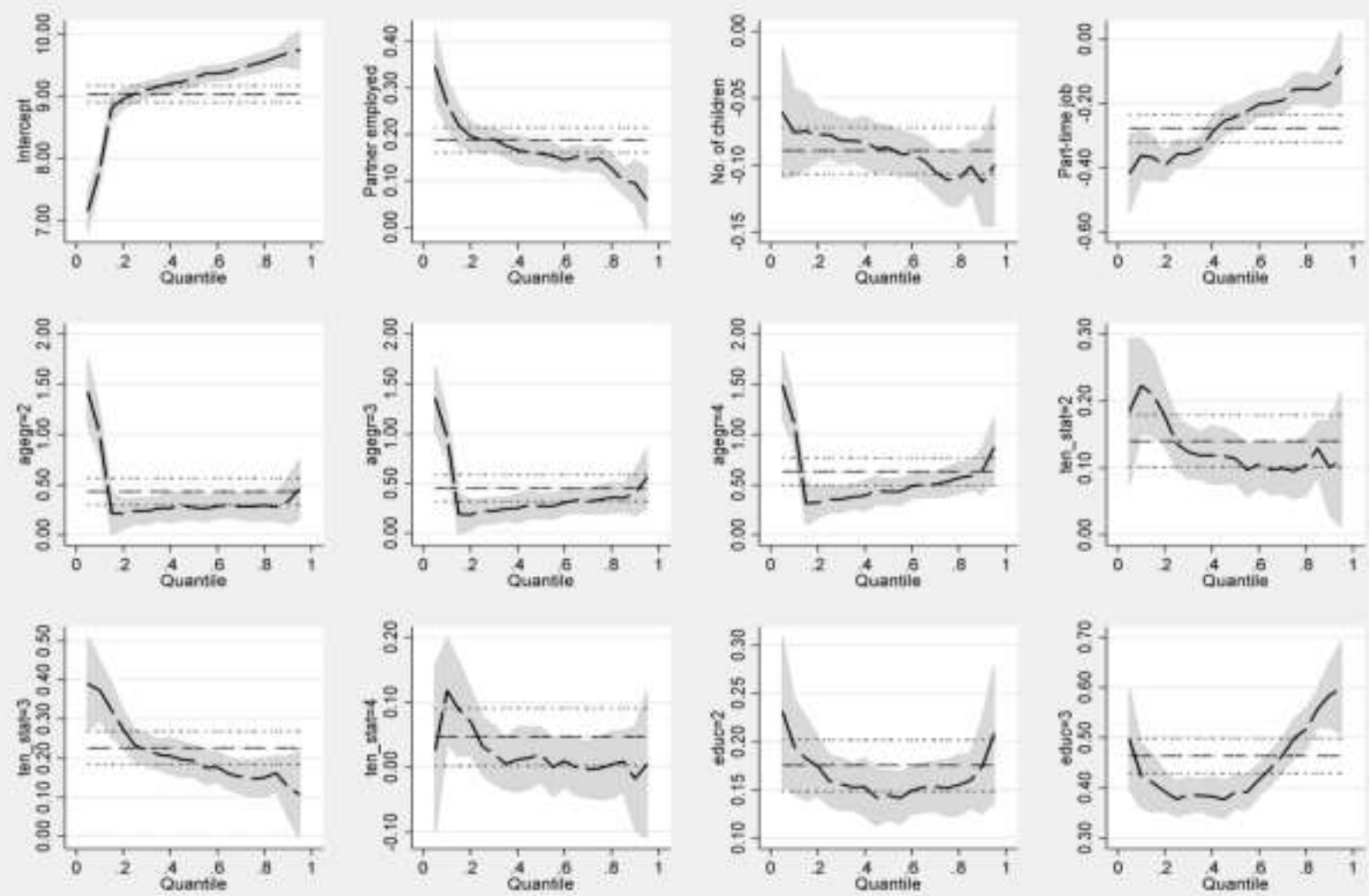

Figure 7 - Quantile regressions (2011) for selected EA countries

(i) Germany (DE)
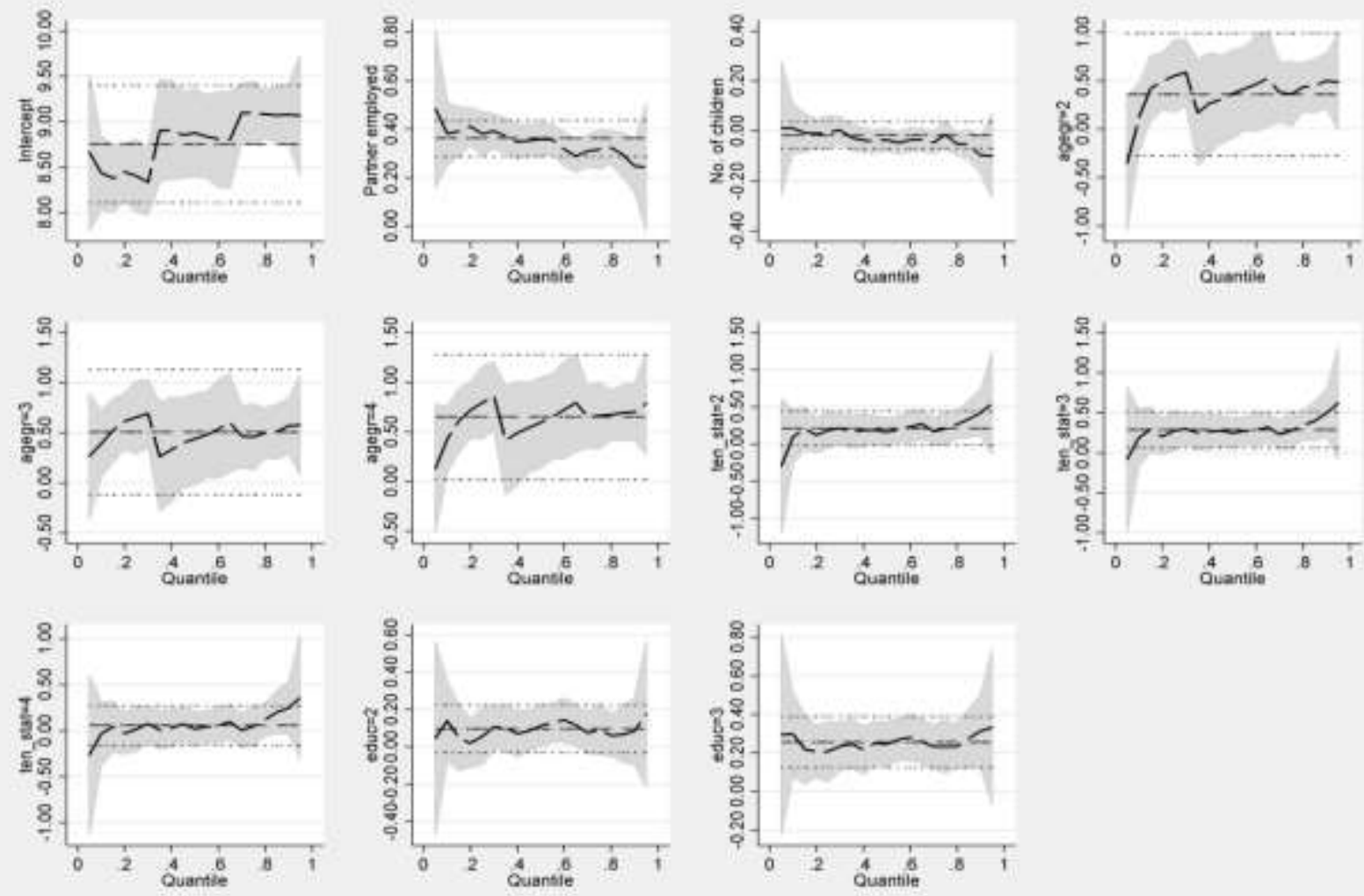
(ii) Spain (ES)
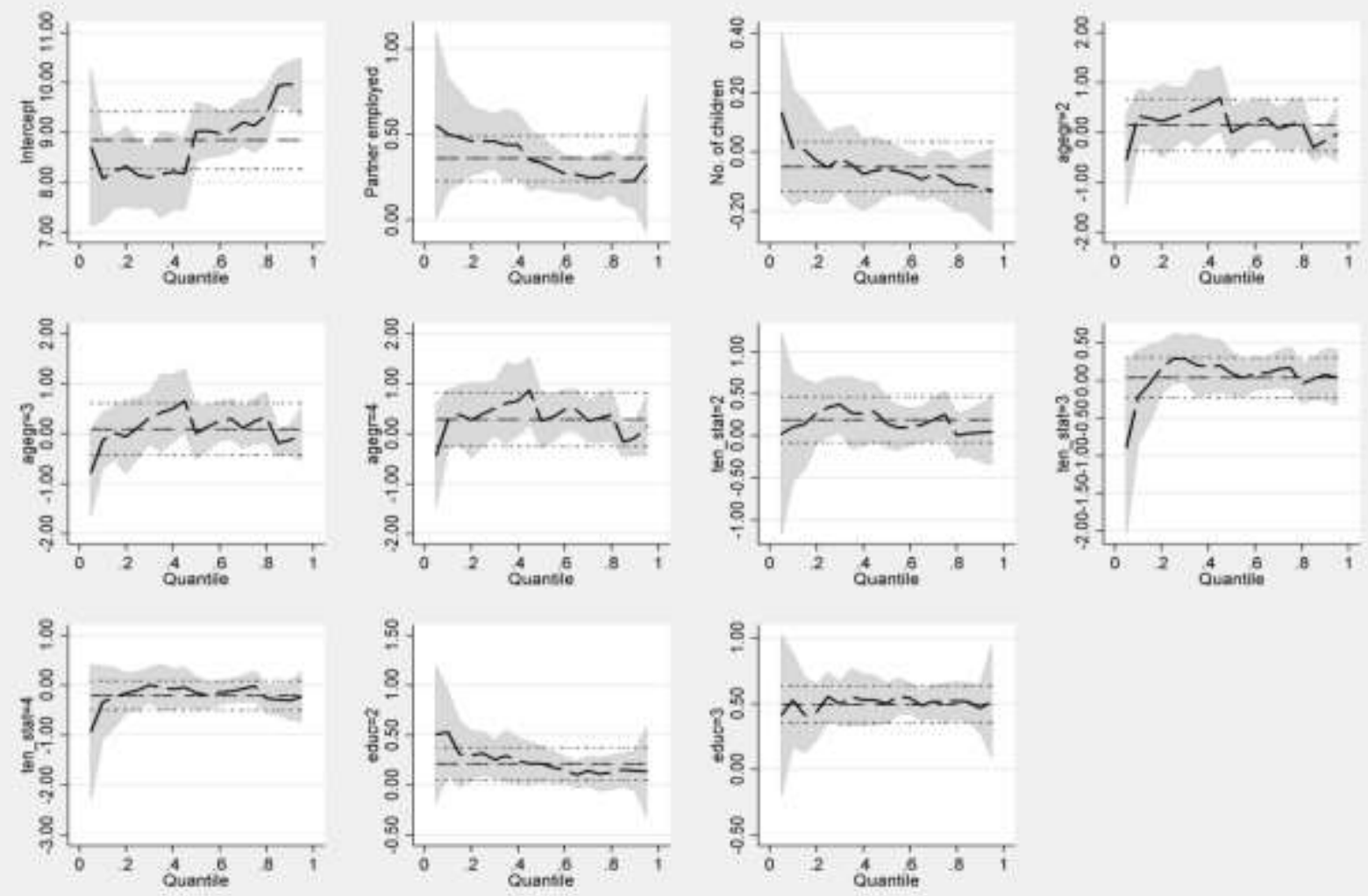

(iii) Italy (IT)
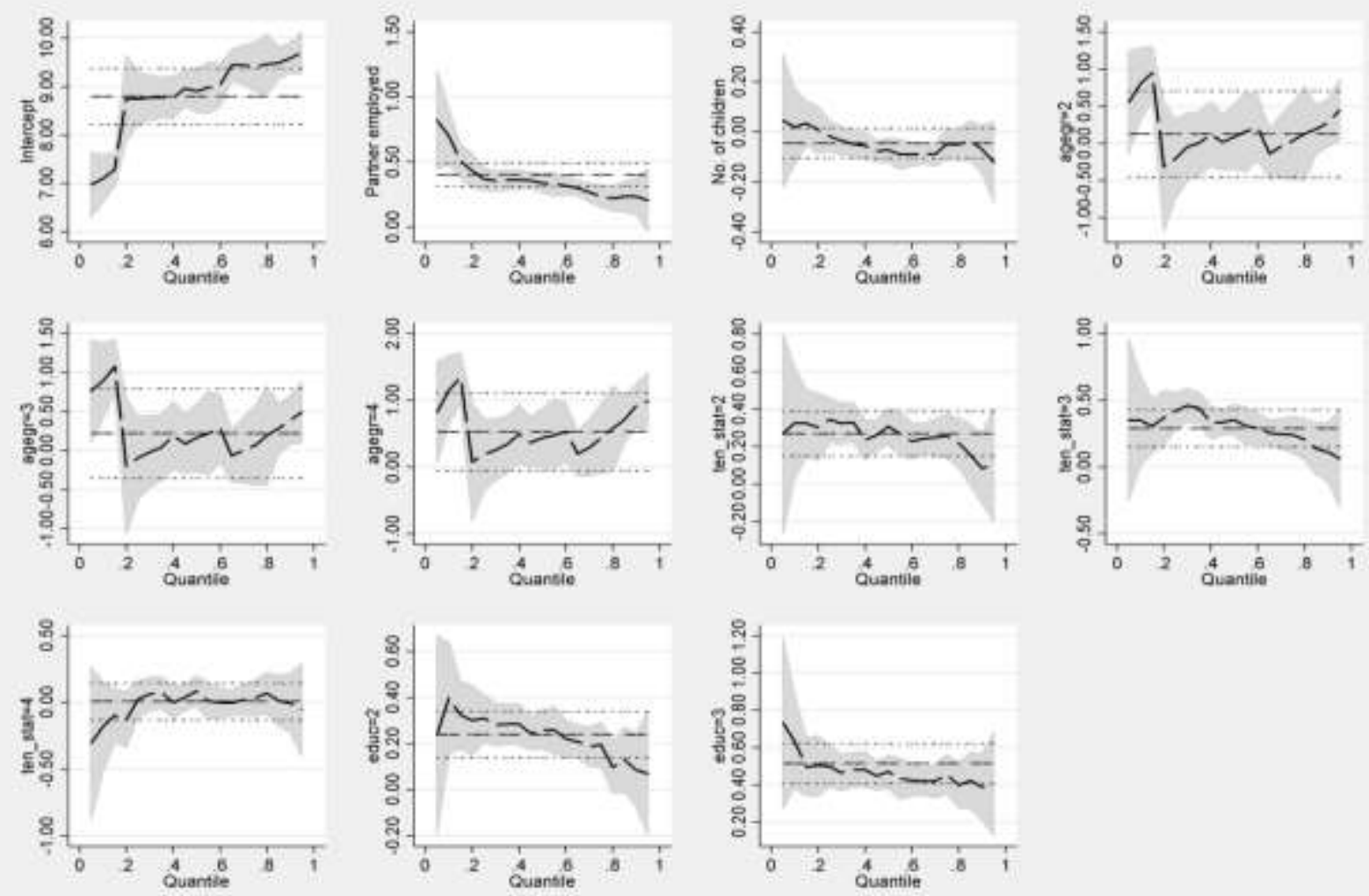


\section{Conclusions}

The aim of the paper was to look at how inequality has evolved in some selected euro area countries (in alphabetical order: Austria (AT), Belgium (BE), Cyprus (CY), Germany (DE), Spain (ES), Finland (FI), France (FR), Greece (GR), Ireland (IE), Italy (IT), the Netherlands (NL), Portugal (PT)) since the start of the crisis and - more importantly - to shed some light on which portions of the income distribution actually drove the observed dynamics in the aggregate, coupled with an analysis of the contribution of the individual income source. Based on household level data from the EU Survey of Income and Living Conditions (EU-SILC), for the cross-sections 2004 to 2011, in the paper we showed a broader set of income inequality indicators, where measures used spanned from the standard Gini index based on household disposable income - thereby allowing a comparison with the results available in the literature - to an alternative indicator, the Zenga index (2007), and an extended income definition. The computation of the Zenga (2007) inequality index, allowed us to detect deviations from equality in any parts of the distribution, including the left (poorest) and the right (richest) parts of the tail, differently from what the Gini index would do. In doing so, the Zenga index was first decomposed into the contribution to overall inequality coming from single income sources. The rationale behind this exercise was to have a quantitative assessment of inequality developments as a result of the economic crisis, especially in those economies which were more hardly hit. Secondly, inequality was further analysed with respect to the aforementioned extended income definition, including additional income components, some of which being particularly relevant in the current conjuncture, such as interest paid on mortgage or private pension plans.

While broadly confirming the distributional effect of the crisis documented in previous studies, we found that, in specific countries, the level of inequality appears higher when alternative measures are taken into account, and that the rise of inequality since 2008 has not been as modest as previous studies would suggest. Exploiting the aforementioned Zenga decomposition, the paper finally looked at how the distribution of income has evolved during the crisis by income quantile groups (i.e. 'zooming-in'). An analysis of income inequality at such a granular level was indeed made possible by the use of the Zenga index (2007) and its linearity property (see Section 4). The results pointed to varying contribution of labour income in 2011 compared to 2007. In addition, looking at the effect of household characteristics on the entire distribution of income, we found that while the impact of such characteristics showed a non-linear pattern across income quantile groups before the crisis; such dispersion has decreased in 201l. This reconciles with the idea that the crisis has possibly "smoothed" the effect of individual characteristics, against other factors (e.g., varying income source share and contributions over time). We argue, on the basis of our analysis, that euro area countries are "differently unequal" in their inequality pattern, particularly when single income sources/quantile groups are examined. Any sensible analysis of the distributional impact of policies adopted during the crisis - particularly in more vulnerable economies - would therefore need to be carried out at a finer level of analysis. 


\section{References}

1. Alesina, A. and Perotti, R. (1996), "Income Distribution, Political Instability and Investment", European Economic Review 40 (1996) 1203- 1228.

2. Atkinson, A.B., L. Rainwater and T. M. Smeeding (1995): "Income distribution in OECD Countries", OECD Social Policy Studies No. 18, Paris 1995.

3. Benabou, R. (1996), "Inequality and Growth", NBER Macroeconomics Annuall996, Volume 11 (p. 11 - 92 Ben S. Bernanke and Julio J. Rotemberg, Eds. MIT Press, ISBN: 0-262-02414-4.

4. Cameron, A. C., and P. K. Trivedi (2010), Microeconometrics Using Stata. Rev. ed. College Station, TX: Stata Press.

5. Carcea, M. and R. Serfling (2014). "Gini Autocovariance Function for Heavy Tailed Time Series Modeling”, Working Paper, http://www.utdallas.edu/_serfling/papers/Gini_autocov_fcn.pdf

6. Chamberlain, G. 1994. Quantile regression, censoring, and the structure of wages. In Advances in Econometrics, Vol. 1: Sixth World Congress, ed. C. A. Sims, 171-209. Cambridge: Cambridge University Press.

7. De Vergottini, M. (1950). "Sugli Indici di Concentrazione" Statistics, X, 445-454.

8. Forbes, K. (2000). "A Reassessment of the Relationship between Inequality and Growth", American Economic Review, 90: 869-97.

9. Galor, O. and Moav, O. (2004), "From Physical to Human Capital Accumulation: Inequality and the Process of Development", The Review of Economic Studies 71, 1001-1026

10. Gini, C. (1912) "Variabilità e mutabilità: contributo allo Studio delle distribuzioni e delle relazioni statistiche". Facoltà di Giurisprudenza della R. Università di Cagliari, anno III, parte 2.

11. Gini C. (1914), "Sulla Misura della Concentrazione e della Variabilità dei Caratteri", in Atti del Reale Istituto Veneto di Scienze, Lettere ed Arti. tomo LXXIII.

12. Greselin, F. M. Puri, R. Zitikis (2009). „L-functions, processes, and statistics in measuring economic inequality and actuarial risks", Statistics and its Interfaces, 2(2), 227-245.

13. Heathcote, J., Perri, F. and G. Violante. (2010). "Unequal We Stand: An Empirical Analysis of Economic Inequality in the United States 1967-2006." Review of Economic Dynamics 13 (January): 15-5l.

14. Jenkins, S., Brandolini, A., Micklewright, J. and B. Nolan (2011), "The Great Recession and the Distribution of Household Income", Fondazione Rodolfo Debenedetti;

15. Keefer, P. and Knack, S. (2002), "Polarization, Politics and Property Rights: Links between Inequality and Growth", Public Choice, Springer, vol. 1ll(1-2), pages 127-54, March

16. Xu, K. (2003), "How has the Literature on Gini's Index Evolved in the Past 80 Years?" Dalhousie University, Economics Working Paper.

17. Lerman R. and Yitzhaki S. (1984). "A Note on the Calculation and Interpretation of the Gini Index", Economics Lettes, 15, 363-368

18. Lerman, R. I. and S. Yitzhaki (1985), "Income Inequality Effects by Income Source: a new Approach and Applications to the United States", Review of Economics and Statistics 67; 151-156.

19. Li H. and H. Zou (1998) "Income Inequality is not Harmful for Growth: Theory and Evidence", Review of Development Economics, 2(3), 318-334.

20. OECD (2008), Growing Unequal? Income Distribution and Poverty in OECD Countries, Paris.

21. OECD (2011), Divided We Stand - Why Inequality Keeps Rising, Paris.

22. OECD (2012), Social spending after the crisis - Social expenditure (SOCX) data update 2012, Paris.

23. Perotti (1993), "Political Equilibrium, Income Distribution, and Growth", Review of Economic Studies;

24. Perotti (1996), “Growth, Income Distribution and Democracy: What the Data Say”, Journal of Economic Growth.

25. Perri, F. and J. Steinberg (2012). "Inequality and redistribution during the Great Recession," Economic Policy Paper 12-1, Federal Reserve Bank of Minneapolis.

26. Petev, Ivaylo D., \& Pistaferri, Luigi. 2012. Consumption in the Great Recession. Stanford, CA: Stanford Center on Poverty and Inequality.

27. Radaelli P. (2010), "On the Decomposition by Subgroups of the Gini Index and Zenga's Uniformity and Inequality Indexes". International Statistical Review, Volume 78, Number 1, Aptile 2010, pp. 81101(21). 
28. Van Kerm P. (2009), "sgini - Generalized Gini and Concentration coefficients (with factor decomposition)" in Stata, vl.l (revised February 2010), CEPS/INSTEAD, Differedange, Luxembourg.

29. Voitchovsky, S. (2005), "Does the Profile of Inequality Matter for Economic Growth?", Journal of Economic Growth, 10, 273-296.

30. World Bank (2002), "Expenditure policies towards EU accession", B. Funck, Poverty Reduction and Economic Management Unit Europe and Central Asia Region, mimeo.

31. Yitzhaki, S. and E. Schechtman (2013), "The Gini Methodology: A Primer on a Statistical Methodology". Springer Series in Statistics 272.

32. Yitzhaki, S. (1997), "More than a Dozen Alternative Ways of Spelling Gini"

33. Zenga, M. (2007), "Inequality curve and inequality index based on the ratios between lower

34. and upper arithmetic means", Statistica \& Applicazioni, V(l), 3-27.

35. Zenga, M.M. Radaelli, P. and Ma. Zenga (2011). "Decomposition of Zenga's inequality index by sources", Statistica e Applicazioni, 2012, 1. 


\section{Annex 1 Additional Charts and Tables}

Figure 1A - Evolution of inequality over the period 2004-11
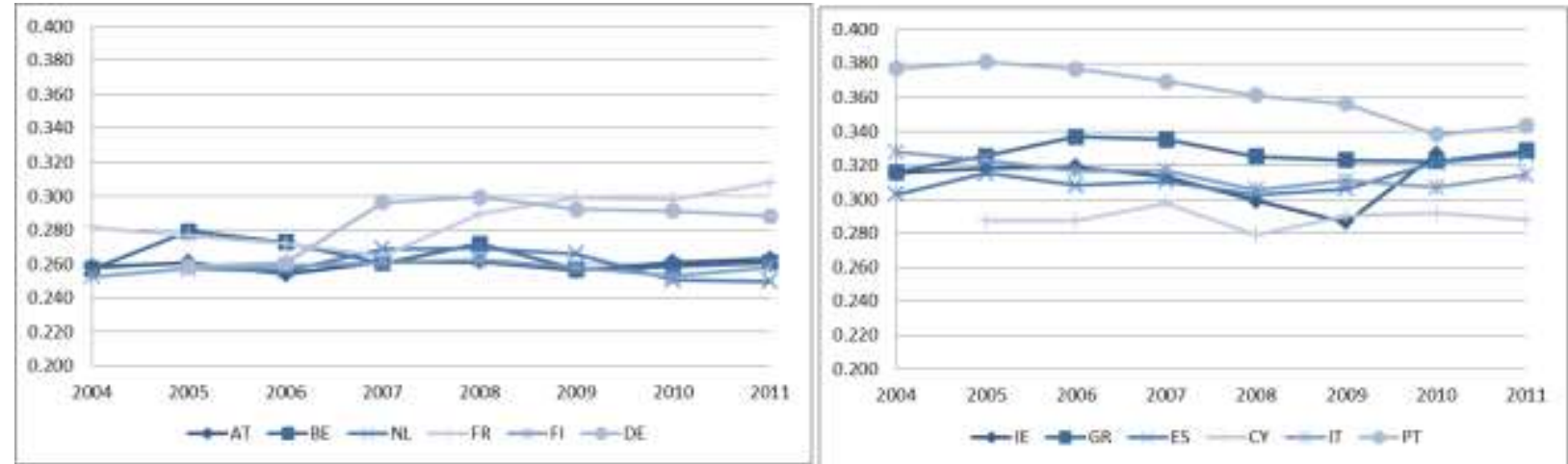
Table 1A - Data coverage

\begin{tabular}{|c|c|c|c|c|c|c|c|c|c|c|}
\hline \multirow{2}{*}{200} & \multicolumn{5}{|c|}{ Income (gross) } & \multicolumn{5}{|c|}{ Disposable income (net) } \\
\hline & Obs & Mean & Std. dev. & Min & $\operatorname{Max}$ & Obs & Mean & Std. dev. & Min & Max \\
\hline AT & 13630 & 29629.8 & 24038.3 & 125.0 & 917119.9 & 13630 & 21460.2 & 14269.3 & 100.0 & 515921.2 \\
\hline $\mathrm{BE}$ & 15076 & 27206.1 & 21647.2 & 10.0 & 848099.3 & 15076 & 20332.2 & 16230.3 & 0.0 & 638000.0 \\
\hline CY & 10022 & 20451.5 & 16838.1 & 925.1 & 717436.4 & 10022 & 18321.7 & 14017.5 & 95.0 & 547746.1 \\
\hline $\mathrm{DE}$ & 28785 & 28667.8 & 22182.8 & 10.0 & 527861.1 & 28785 & 21325.7 & 15242.3 & 2.0 & 468704.7 \\
\hline ES & 35665 & 16491.9 & 10773.3 & 3.8 & 132516.7 & 35665 & 14054.6 & 8378.2 & 3.3 & 113724.3 \\
\hline FI & 26466 & 32048.3 & 23490.9 & 164.0 & 654971.3 & 26466 & 23552.5 & 15658.8 & 118.0 & 521733.3 \\
\hline FR & 25501 & 28381.3 & 25850.2 & 123.2 & 1207745.0 & 25501 & 23000.9 & 18029.7 & 124.0 & 577813.3 \\
\hline \multicolumn{11}{|l|}{ GR } \\
\hline IE & 12543 & 31584.6 & 28571.9 & 150.0 & 501777.7 & 12543 & 26639.7 & 20981.5 & 120.0 & 476915.1 \\
\hline IT & 52145 & 24137.7 & 19090.8 & 27.7 & 562091.3 & 52145 & 18150.6 & 12120.2 & 55.0 & 315193.3 \\
\hline NL & 25381 & 36464.3 & 26579.9 & 759.0 & 1151297.0 & 25381 & 23997.5 & 15523.0 & 268.5 & 479948.1 \\
\hline PT & 11786 & 12397.0 & 12237.0 & 333.3 & 228604.4 & 11786 & 9896.0 & 8458.8 & 286.7 & 137971.8 \\
\hline \multicolumn{11}{|c|}{2005} \\
\hline & Obs & Mean & Std. dev. & Min & Max & Obs & Mean & Std. dev. & Min & Max \\
\hline AT & 5710 & 29568.2 & 22762.8 & 125.0 & 917119.9 & 5710 & 21389.5 & 13795.9 & 100.0 & 515921.2 \\
\hline $\mathrm{BE}$ & 6285 & 26245.4 & 22323.7 & 10.0 & 848099.3 & 6285 & 19823.4 & 16486.0 & 0.0 & 638000.0 \\
\hline CY & 3353 & 19853.9 & 18708.8 & 925.1 & 717436.4 & 3353 & 17775.6 & 15353.4 & 95.0 & 547746.1 \\
\hline $\mathrm{DE}$ & 13212 & 28395.4 & 23078.9 & 10.0 & 527861.1 & 13212 & 21161.6 & 15731.1 & 2.0 & 468704.7 \\
\hline ES & 12886 & 16489.1 & 11176.2 & 3.8 & 132516.7 & 12886 & 14092.6 & 8638.4 & 3.3 & 113724.3 \\
\hline FI & 10462 & 31536.3 & 25061.3 & 164.0 & 654971.3 & 10462 & 23202.2 & 16763.4 & 118.0 & 521733.3 \\
\hline FR & 10412 & 28616.6 & 26698.7 & 123.2 & 1207745.0 & 10412 & 23278.8 & 18504.3 & 124.0 & 577813.3 \\
\hline \multicolumn{11}{|l|}{ GR } \\
\hline IE & 5239 & 29667.6 & 27834.1 & 150.0 & 501777.7 & 5239 & 25388.8 & 20416.9 & 120.0 & 476915.1 \\
\hline IT & 20760 & 23977.7 & 19791.8 & 27.7 & 562091.3 & 20760 & 18091.0 & 12523.8 & 55.0 & 315193.3 \\
\hline NL & 10304 & 36370.1 & 28033.4 & 759.0 & 1151297.0 & 10304 & 24070.6 & 15727.9 & 268.5 & 479948.1 \\
\hline PT & 4439 & 12150.9 & 12397.0 & 333.3 & 228604.4 & 4439 & 9837.6 & 8661.9 & 286.7 & 137971.8 \\
\hline \multicolumn{11}{|c|}{2006} \\
\hline & Obs & Mean & Std. dev. & Min & Max & Obs & Mean & Std. dev. & Min & Max \\
\hline AT & 13606 & 30424.3 & 19588.3 & 20.0 & 337998.5 & 13606 & 22216.9 & 11880.1 & 16.0 & 204100.0 \\
\hline $\mathrm{BE}$ & 14678 & 27981.4 & 19527.3 & 19.4 & 651843.5 & 14678 & 21214.9 & 13722.0 & 19.4 & 604689.5 \\
\hline $\mathrm{CY}$ & 9281 & 21248.6 & 17441.5 & 1360.0 & 698266.7 & 9281 & 18950.1 & 14546.8 & 1040.0 & 537733.3 \\
\hline $\mathrm{DE}$ & 28336 & 28476.8 & 20027.9 & 10.0 & 518000.0 & 28336 & 21355.7 & 13949.1 & 10.0 & 454760.0 \\
\hline ES & 36158 & 16969.0 & 11087.7 & 2.6 & 183946.7 & 13524 & 6523.6 & 3736.5 & 2.0 & 40388.8 \\
\hline FI & 25141 & 33359.9 & 23973.7 & 200.0 & 688763.0 & 36158 & 14592.3 & 8750.6 & 2.0 & 177166.0 \\
\hline FR & 25595 & 29053.5 & 26693.5 & 11.0 & 1152651.0 & 25595 & 23655.5 & 19740.1 & 10.0 & 661973.3 \\
\hline GR & 17855 & 17303.4 & 15519.1 & 30.9 & 299704.8 & 17855 & 13049.2 & 9922.4 & 27.8 & 173684.8 \\
\hline IE & 12631 & 30941.5 & 25187.0 & 4.4 & 351066.9 & 12631 & 25854.8 & 16546.9 & 3.3 & 250374.4 \\
\hline IT & 50962 & 24881.7 & 20801.1 & 2.5 & 579040.0 & 50962 & 18673.0 & 13221.8 & 2.5 & 333388.0 \\
\hline NL & 23640 & 37882.3 & 26581.4 & 1020.0 & 1412640.0 & 23640 & 24539.2 & 14771.8 & 263.8 & 631358.0 \\
\hline PT & 13013 & 12359.5 & 12374.0 & 168.0 & 247578.7 & 13013 & 9969.9 & 8641.9 & 168.0 & 197171.3 \\
\hline \multicolumn{11}{|c|}{2007} \\
\hline & Obs & Mean & Std. dev. & Min & Max & Obs & Mean & Std. dev. & Min & Max \\
\hline
\end{tabular}




\begin{tabular}{|c|c|c|c|c|c|c|c|c|c|c|}
\hline AT & 5874 & 30503.0 & 20565.1 & 20.0 & 337998.5 & 5874 & 22202.2 & 12606.1 & 16.0 & 204100.0 \\
\hline $\mathrm{BE}$ & 6105 & 27414.9 & 21707.7 & 19.4 & 651843.5 & 6105 & 20987.3 & 15070.3 & 19.4 & 604689.5 \\
\hline CY & 3142 & 20591.2 & 19657.5 & 1360.0 & 698266.7 & 3142 & 18402.8 & 16360.5 & 1040.0 & 537733.3 \\
\hline $\mathrm{DE}$ & 13024 & 28124.4 & 20731.5 & 10.0 & 518000.0 & 13024 & 21132.2 & 14273.6 & 10.0 & 454760.0 \\
\hline ES & 13087 & 17064.5 & 11511.2 & 2.6 & 183946.7 & 13087 & 14725.5 & 9059.3 & 2.0 & 177166.0 \\
\hline FI & 10123 & 32699.6 & 25636.5 & 200.0 & 688763.0 & 10123 & 24189.7 & 17109.1 & 0.0 & 563315.0 \\
\hline FR & 10595 & 29545.4 & 28240.5 & 11.0 & 1152651.0 & 10595 & 24139.4 & 20913.3 & 10.0 & 661973.3 \\
\hline GR & 6934 & 16784.1 & 15568.8 & 197.0 & 299704.8 & 6934 & 12921.3 & 9933.2 & 30.0 & 173684.8 \\
\hline IE & 5169 & 29437.0 & 25270.9 & 4.4 & 351066.9 & 5169 & 24977.9 & 17117.2 & 3.3 & 250374.4 \\
\hline IT & 20355 & 24852.6 & 21745.5 & 2.5 & 579040.0 & 20355 & 18727.8 & 13793.2 & 2.5 & 333388.0 \\
\hline NL & 9706 & 37806.0 & 29369.7 & 1020.0 & 1412640.0 & 9706 & 24657.0 & 16043.4 & 263.8 & 631358.0 \\
\hline PT & 4949 & 12223.3 & 12463.9 & 168.0 & 247578.7 & 4949 & 9987.1 & 8762.0 & 168.0 & 197171.3 \\
\hline \multicolumn{11}{|c|}{2008} \\
\hline & Obs & Mean & Std. dev. & Min & Max & Obs & Mean & Std. dev. & Min & Max \\
\hline AT & 14085 & 32084.2 & 21850.2 & 83.8 & 325500.0 & 14085 & 23342.4 & 12967.4 & 67.0 & 204627.4 \\
\hline $\mathrm{BE}$ & 14734 & 28458.6 & 18074.8 & 125.0 & 442721.6 & 14734 & 21339.0 & 12799.0 & 125.0 & 424382.7 \\
\hline $\mathrm{CY}$ & 11081 & 21583.9 & 18325.9 & 793.3 & 748666.7 & 11081 & 19064.2 & 15899.5 & 480.0 & 709977.3 \\
\hline $\mathrm{DE}$ & 27935 & 28961.2 & 25262.8 & 0.7 & 1644722.0 & 27935 & 21567.1 & 15962.3 & 68.0 & 838842.0 \\
\hline ES & 36306 & 16976.0 & 11528.5 & 1.2 & 152728.3 & 36306 & 14629.7 & 9182.9 & 0.6 & 149385.0 \\
\hline FI & 26994 & 33792.7 & 25011.0 & 38.0 & 686814.0 & 26994 & 25252.1 & 16637.1 & 0.0 & 544886.0 \\
\hline FR & 26504 & 29258.7 & 23806.7 & 666.7 & 883162.0 & 26504 & 23938.3 & 17592.4 & 180.0 & 421666.7 \\
\hline GR & 17496 & 17209.8 & 15220.5 & 80.0 & 244896.1 & 17496 & 13118.6 & 9663.6 & 0.0 & 152836.0 \\
\hline IE & 11550 & 28846.1 & 29979.5 & 25.0 & 850267.0 & 11550 & 23515.5 & 17993.4 & 0.0 & 475721.8 \\
\hline IT & 47296 & 24997.5 & 21476.9 & 4.3 & 994962.9 & 47296 & 18811.2 & 13468.3 & 4.3 & 571587.2 \\
\hline NL & 24564 & 38132.8 & 24034.2 & 936.0 & 1025993.0 & 24564 & 24638.7 & 13140.9 & 146.0 & 549589.3 \\
\hline PT & 13368 & 12375.4 & 10731.9 & 207.0 & 141185.4 & 13368 & 10045.1 & 7407.9 & 207.0 & 88236.5 \\
\hline \multicolumn{11}{|c|}{2009} \\
\hline & Obs & Mean & Std. dev. & Min & $\operatorname{Max}$ & Obs & Mean & Std. dev. & Min & $\operatorname{Max}$ \\
\hline AT & 6186 & 32027.6 & 22372.9 & 83.8 & 325500.0 & 6186 & 23281.8 & 13364.9 & 67.0 & 204627.4 \\
\hline $\mathrm{BE}$ & 6121 & 27667.5 & 18876.0 & 125.0 & 442721.6 & 6121 & 20959.2 & 13534.0 & 125.0 & 424382.7 \\
\hline $\mathrm{CY}$ & 3776 & 20952.3 & 20043.6 & 793.3 & 748666.7 & 3776 & 18510.0 & 17501.2 & 480.0 & 709977.3 \\
\hline $\mathrm{DE}$ & 13005 & 28817.3 & 28235.7 & 0.7 & 1644722.0 & 13005 & 21516.4 & 17528.8 & 68.0 & 838842.0 \\
\hline ES & 13307 & 17044.7 & 11750.7 & 1.2 & 152728.3 & 13307 & 14744.9 & 9330.0 & 0.6 & 149385.0 \\
\hline FI & 10977 & 33128.0 & 26353.5 & 38.0 & 686814.0 & 10977 & 24824.1 & 17628.5 & 0.0 & 544886.0 \\
\hline FR & 11031 & 29590.9 & 24408.8 & 666.7 & 883162.0 & 11031 & 24272.6 & 17811.5 & 180.0 & 421666.7 \\
\hline GR & 6937 & 16695.6 & 15091.1 & 80.0 & 244896.1 & 6937 & 12980.8 & 9560.2 & 80.0 & 152836.0 \\
\hline IE & 4613 & 27646.7 & 26091.4 & 25.0 & 850267.0 & 4613 & 23040.2 & 16314.7 & 0.0 & 475721.8 \\
\hline IT & 18998 & 25074.7 & 21700.8 & 4.3 & 994962.9 & 18998 & 18930.5 & 13594.2 & 4.3 & 571587.2 \\
\hline NL & 10103 & 38165.2 & 25217.5 & 936.0 & 1025993.0 & 10103 & 24813.5 & 13742.6 & 146.0 & 549589.3 \\
\hline PT & 5166 & 12175.4 & 11099.5 & 207.0 & 141185.4 & 5166 & 10021.8 & 7707.8 & 207.0 & 88236.5 \\
\hline \multicolumn{11}{|c|}{2010} \\
\hline & Obs & Mean & Std. dev. & Min & $\operatorname{Max}$ & Obs & Mean & Std. dev. & Min & $\operatorname{Max}$ \\
\hline AT & 13927 & 32863.6 & 22361.2 & 12.5 & 491750.3 & 13927 & 24172.5 & 13895.8 & 10.0 & 292774.2 \\
\hline $\mathrm{BE}$ & 14276 & 28777.8 & 27172.7 & 47.6 & 2529400.0 & 14276 & 21861.8 & 17938.6 & 47.6 & 1684067.0 \\
\hline $\mathrm{CY}$ & 11438 & 22603.6 & 18539.6 & 645.0 & 802944.7 & 11438 & 19847.3 & 16294.6 & 520.0 & 766834.7 \\
\hline $\mathrm{DE}$ & 28580 & 29618.3 & 22879.1 & 31.0 & 1050177.0 & 28580 & 22087.6 & 15490.7 & 31.0 & 587974.0 \\
\hline ES & 34146 & 16430.8 & 11121.3 & 3.1 & 117600.0 & 34146 & 14225.5 & 8976.1 & 2.5 & 117600.0 \\
\hline
\end{tabular}




\begin{tabular}{|c|c|c|c|c|c|c|c|c|c|c|}
\hline FI & 23008 & 34927.0 & 33472.5 & 12.0 & 2401212.0 & 23008 & 26191.6 & 24463.0 & 0.0 & 1888896.0 \\
\hline FR & 27050 & 30014.7 & 31820.5 & 65.0 & 1311026.0 & 27050 & 24342.1 & 23668.3 & 60.0 & 922660.0 \\
\hline GR & 14932 & 15046.7 & 12816.8 & 120.0 & 263483.2 & 14932 & 11591.3 & 8441.2 & 0.0 & 181666.7 \\
\hline IE & 10979 & 28107.9 & 22805.9 & 19.1 & 361525.1 & 10979 & 22776.6 & 14308.3 & 15.0 & 218626.3 \\
\hline IT & 47548 & 25973.7 & 29325.6 & 4.0 & 1964900.0 & 47548 & 19311.2 & 17528.2 & 0.0 & 1091677.0 \\
\hline NL & 25408 & 38701.0 & 25936.1 & 40.0 & 1323389.0 & 25408 & 24628.1 & 13303.7 & 40.0 & 539086.0 \\
\hline PT & 14660 & 12486.1 & 11140.1 & 254.5 & 154309.6 & 14660 & 9985.8 & 7576.4 & 254.5 & 127968.1 \\
\hline \multicolumn{11}{|c|}{2011} \\
\hline & Obs & Mean & Std. dev. & Min & Max & Obs & Mean & Std. dev. & Min & Max \\
\hline AT & 6183 & 32729.7 & 23244.3 & 12.5 & 491750.3 & 6183 & 24088.1 & 14438.8 & 10.0 & 292774.2 \\
\hline $\mathrm{BE}$ & 5895 & 28338.5 & 37259.9 & 47.6 & 2529400.0 & 5895 & 21729.6 & 24756.3 & 47.6 & 1684067.0 \\
\hline CY & 3914 & 22220.5 & 20776.7 & 645.0 & 802944.7 & 3914 & 19522.8 & 18415.8 & 520.0 & 766834.7 \\
\hline $\mathrm{DE}$ & 13418 & 29254.2 & 23456.8 & 31.0 & 1050177.0 & 13418 & 21885.9 & 15848.3 & 31.0 & 587974.0 \\
\hline ES & 12841 & 16556.2 & 11462.1 & 3.1 & 117600.0 & 12841 & 14401.4 & 9217.9 & 2.5 & 117600.0 \\
\hline FI & 9343 & 34319.1 & 37349.4 & 12.0 & 2401212.0 & 9343 & 25858.4 & 27602.8 & 0.0 & 1888896.0 \\
\hline FR & 11345 & 30302.4 & 30398.2 & 65.0 & 1311026.0 & 11345 & 24694.3 & 22446.3 & 60.0 & 922660.0 \\
\hline GR & 5942 & 14644.5 & 12788.1 & 120.0 & 263483.2 & 5942 & 11403.5 & 8422.1 & 0.0 & 181666.7 \\
\hline \multicolumn{11}{|l|}{ IE } \\
\hline IT & 19227 & 26093.7 & 28698.4 & 4.0 & 1964900.0 & 19227 & 19495.1 & 17293.8 & 0.0 & 1091677.0 \\
\hline NL & 10469 & 38735.2 & 27112.2 & 40.0 & 1323389.0 & 10469 & 24793.1 & 13936.7 & 40.0 & 539086.0 \\
\hline PT & 5725 & 12383.8 & 11554.0 & 254.5 & 154309.6 & 5725 & 10033.8 & 7900.0 & 254.5 & 127968.1 \\
\hline
\end{tabular}


Table 2A - Contribution of income sources - net extended income (Gini index=100)

\begin{tabular}{|c|c|c|c|c|c|c|}
\hline & & $2005-2007$ & 2008 & 2009 & 2010 & 2011 \\
\hline \multirow[t]{7}{*}{ AT } & Labour income & 101.1 & 112.7 & 110.2 & 115.1 & 108.4 \\
\hline & Self-empl. lab. income & 21.2 & 17.8 & 22.2 & 21.1 & 19.3 \\
\hline & Non-cash lab. income (ext) & 0.0 & 0.0 & 0.0 & 0.0 & 0.0 \\
\hline & Cash transfers & 20.3 & 15.9 & 13.7 & 11.7 & 15.9 \\
\hline & Other income (ext) & 6.2 & 9.4 & 7.3 & 8.7 & 10.1 \\
\hline & Interests on mortg. & -0.4 & -0.7 & -0.5 & -0.7 & -0.7 \\
\hline & Taxes & -48.7 & -55.2 & -52.9 & -56.0 & -53.7 \\
\hline \multirow[t]{7}{*}{$\mathrm{BE}$} & Labour income & 134.7 & 125.2 & 131.9 & 129.9 & 136.4 \\
\hline & Self-empl. lab. income & 16.9 & 22.1 & 13.3 & 12.0 & 14.9 \\
\hline & Non-cash lab. income (ext) & 1.0 & 1.1 & 1.3 & 1.1 & 1.2 \\
\hline & Cash transfers & -7.6 & -6.6 & -4.2 & -3.3 & -7.9 \\
\hline & Other income (ext) & 12.4 & 9.5 & 9.5 & 12.4 & 8.9 \\
\hline & Interests on mortg. & -1.8 & -1.9 & -1.9 & -2.1 & -2.3 \\
\hline & Taxes & -55.6 & -49.4 & -49.9 & -50.0 & -52.1 \\
\hline \multirow[t]{7}{*}{$\mathrm{CY}$} & Labour income & 90.8 & 91.0 & 90.3 & 95.0 & 95.0 \\
\hline & Self-empl. lab. income & 12.0 & 13.9 & 12.2 & 11.3 & 10.1 \\
\hline & Non-cash lab. income (ext) & 0.4 & 0.4 & 0.3 & 0.4 & 0.3 \\
\hline & Cash transfers & 5.1 & 5.3 & 8.9 & 8.1 & 7.6 \\
\hline & Other income (ext) & 8.9 & 7.4 & 7.2 & 6.0 & 7.5 \\
\hline & Interests on mortg. & & -1.1 & -1.2 & -1.2 & -1.2 \\
\hline & Taxes & -16.8 & -16.8 & -17.7 & -19.5 & -20.3 \\
\hline \multirow[t]{7}{*}{$\mathrm{DE}$} & Labour income & 106.6 & 106.6 & 112.7 & 115.3 & 114.0 \\
\hline & Self-empl. lab. income & 25.2 & 27.9 & 22.8 & 18.8 & 16.9 \\
\hline & Non-cash lab. income (ext) & 1.4 & 2.1 & 2.1 & 2.1 & 1.6 \\
\hline & Cash transfers & 2.9 & 2.6 & 1.7 & 4.6 & 6.5 \\
\hline & Other income (ext) & 8.4 & 8.4 & 7.5 & 10.9 & 9.6 \\
\hline & Interests on mortg. & -0.1 & 0.0 & 0.0 & -1.5 & -1.7 \\
\hline & Taxes & -44.4 & -47.7 & -46.9 & -50.0 & -48.1 \\
\hline \multirow[t]{7}{*}{ ES } & Labour income & 70.0 & 107.6 & 103.7 & 99.5 & 95.5 \\
\hline & Self-empl. lab. income & 5.8 & 6.7 & 7.0 & 10.1 & 11.3 \\
\hline & Non-cash lab. income (ext) & 0.4 & 1.0 & 0.8 & 0.7 & 0.5 \\
\hline & Cash transfers & 3.8 & 6.2 & 7.5 & 8.0 & 9.8 \\
\hline & Other income (ext) & 3.3 & 5.4 & 5.8 & 5.5 & 4.5 \\
\hline & Interests on mortg. & & -1.3 & -1.1 & -1.0 & -0.8 \\
\hline & Taxes & -16.3 & -25.6 & -23.6 & -22.8 & -21.7 \\
\hline \multirow[t]{4}{*}{ FI } & Labour income & 132.3 & 126.7 & 130.4 & 129.6 & 121.6 \\
\hline & Self-empl. lab. income & 13.5 & 16.3 & 14.5 & 11.4 & 11.2 \\
\hline & Non-cash lab. income (ext) & 2.1 & 2.1 & 1.9 & 2.0 & 1.7 \\
\hline & Cash transfers & -11.4 & -9.1 & -9.4 & -7.5 & -7.0 \\
\hline
\end{tabular}




\begin{tabular}{|c|c|c|c|c|c|c|}
\hline & Other income (ext) & 24.5 & 21.1 & 20.6 & 19.3 & 21.1 \\
\hline & Interests on mortg. & -1.9 & -2.8 & -2.8 & -2.1 & -1.4 \\
\hline & Taxes & -59.1 & -54.4 & -55.3 & -52.8 & -50.4 \\
\hline \multirow[t]{7}{*}{ FR } & Labour income & 93.3 & 66.7 & 68.0 & 70.1 & 70.2 \\
\hline & Self-empl. lab. income & 17.5 & 16.0 & 15.9 & 13.1 & 13.9 \\
\hline & Non-cash lab. income (ext) & 0.0 & 0.0 & 0.0 & 0.0 & 0.0 \\
\hline & Cash transfers & 19.9 & 18.8 & 15.7 & 18.6 & 18.1 \\
\hline & Other income (ext) & 9.0 & 31.4 & 32.7 & 29.4 & 30.8 \\
\hline & Interests on mortg. & -1.2 & -0.5 & -0.8 & -0.7 & -0.7 \\
\hline & Taxes & -38.5 & -29.4 & -31.5 & -30.5 & -32.4 \\
\hline \multirow[t]{7}{*}{ GR } & Labour income & 82.9 & 85.2 & 81.6 & 76.4 & 76.5 \\
\hline & Self-empl. lab. income & 42.2 & 39.4 & 39.3 & 42.2 & 39.2 \\
\hline & Non-cash lab. income (ext) & 0.3 & 0.3 & 0.3 & 0.3 & 0.3 \\
\hline & Cash transfers & 15.4 & 16.1 & 16.3 & 16.2 & 16.7 \\
\hline & Other income (ext) & 10.1 & 8.8 & 8.6 & 9.7 & 9.3 \\
\hline & Interests on mortg. & -0.8 & -0.8 & -0.6 & -0.6 & -0.5 \\
\hline & Taxes & -50.1 & -49.0 & -45.5 & -44.3 & -41.4 \\
\hline \multirow[t]{7}{*}{ IE } & Labour income & 106.4 & 110.4 & 120.0 & 112.5 & . \\
\hline & Self-empl. lab. income & 32.0 & 25.2 & 23.2 & 15.5 & . \\
\hline & Non-cash lab. income (ext) & 0.7 & 0.8 & 0.5 & 0.5 & . \\
\hline & Cash transfers & -6.1 & -5.6 & -4.8 & 4.6 & . \\
\hline & Other income (ext) & 6.4 & 9.3 & 5.6 & 4.4 & . \\
\hline & Interests on mortg. & -2.2 & -2.6 & -3.6 & -2.5 & . \\
\hline & Taxes & -37.1 & -37.5 & -40.8 & -34.9 & . \\
\hline \multirow[t]{7}{*}{ IT } & Labour income & 75.4 & 70.9 & 70.6 & 70.1 & 70.6 \\
\hline & Self-empl. lab. income & 41.7 & 47.5 & 43.4 & 44.8 & 42.0 \\
\hline & Non-cash lab. income (ext) & 0.2 & 0.3 & 0.3 & 0.3 & 0.3 \\
\hline & Cash transfers & 22.2 & 24.7 & 26.5 & 26.9 & 27.5 \\
\hline & Other income (ext) & 6.6 & 7.6 & 7.8 & 6.9 & 8.2 \\
\hline & Interests on mortg. & -0.6 & -0.4 & -0.4 & -0.4 & -0.5 \\
\hline & Taxes & -45.5 & -50.6 & -48.2 & -48.6 & -48.8 \\
\hline \multirow[t]{7}{*}{ NL } & Labour income & 121.7 & 119.7 & 118.6 & 126.8 & 127.3 \\
\hline & Self-empl. lab. income & 20.8 & 28.5 & 30.2 & 27.9 & 29.0 \\
\hline & Non-cash lab. income (ext) & 2.4 & 2.7 & 2.9 & 2.4 & 2.2 \\
\hline & Cash transfers & 12.4 & 10.7 & 12.5 & 13.4 & 13.5 \\
\hline & Other income (ext) & 12.6 & 20.5 & 18.4 & 11.1 & 12.1 \\
\hline & Interests on mortg. & -3.4 & -7.0 & -6.0 & -5.5 & -5.7 \\
\hline & Taxes & -66.5 & -75.1 & -76.6 & -76.2 & -79.4 \\
\hline \multirow[t]{3}{*}{ PT } & Labour income & 102.5 & 96.7 & 96.3 & 104.7 & 103.9 \\
\hline & Self-empl. lab. income & 16.0 & 20.9 & 20.1 & 12.3 & 12.1 \\
\hline & Non-cash lab. income (ext) & 1.0 & 0.0 & 0.0 & 0.2 & 0.3 \\
\hline
\end{tabular}




\begin{tabular}{|l|c|c|c|c|c|}
\hline Cash transfers & 21.3 & 20.6 & 18.7 & 18.1 & 21.2 \\
\hline Other income (ext) & 3.2 & 3.7 & 4.4 & 5.5 & 4.4 \\
\hline Interests on mortg. & -1.3 & -1.6 & -1.1 & -1.3 & -1.0 \\
\hline Taxes & -42.7 & -40.3 & -38.5 & -39.6 & -41.4 \\
\hline
\end{tabular}

Note: The euro area countries considered are (in alphabetical order) Austria (AT), Belgium (BE), Cyprus (CY), Germany (DE), Spain (ES), Finland (FI), France (FR), Greece (GR), Ireland (IE), Italy (IT), the Netherlands (NL), Portugal (PT). Contribution of single income sources normalized onto overall inequality (Gini index $=100$ ). 


\section{Annex 2 Treatment of 'residuals'}

As discussed in our data Section, consistent with the assumption of income (whether gross or net) adding up to the sum of the individual income sources, a residual component is included in the contribution of income components to aggregate income. Here, the residual component represents the part of income which is not accounted for by the available income decomposition sources in the EU-SILC (i.e. the sum of individual income sources does not always add up to total household income, as in Table l).

There might be a number of reasons why one should expect such a discrepancy measure to appear in the data. First, survey answers may go wrong as people can forget, make mistakes or simply do not respond. Secondly, people may be reluctant to disclose the full extent of their income (e.g., coming from illegal activities, tax evasion, etc.). Finally, some parts of income, retained profits and/or related costs may be difficult to quantify (see also World Bank, 2001). In our analysis, such a discrepancy results in an observed income indicator which contains an additive error term. This may cast some doubts on the interpretation of the income sources and the decomposition exercise outlined previously.

In order to test for the statistical significance of the residual and investigate the robustness of our results to such a 'residual' component, we estimate bootstrapped confidence bands for the Gini coefficient in each country. The bootstrapped standard errors and estimates for Gini inequality index are calculated on total income. The Gini coefficient so obtained, together with bootstrapped two-standard errors confidence bands, is plotted against the Gini coefficient calculated as the sum of the individual income components. The divergence between the two is simply explained by the existence of a 'residual'. Hence, the possibility that the Gini index calculated on the sum of the income sources falls in between the bootstrapped confidence bands for the Gini calculated on total income provides an indirect test for the statistical significance of the residual in our series. The Gini coefficient calculated on the sum of the income components gets, in all cases, close to the index calculated on total income series, soundly rejecting the hypothesis that the residual is statistically significant. Nonetheless, it is less so for Spain for the years 2004 and 2005, where the Gini coefficient calculated on the sum of the individual income sources moves away from the one calculated on total income and outside the estimated confidence bands.

Overall, however, also in the case of Spain the pattern that emerges from leaving the residual in the income decomposition exercise differs negligibly from an analysis where the residual is spread onto the other income components, in proportion to each component contribution to the overall income. Hence, the analysis is performed without considering an explicit 'residual' component in the decomposition exercise by income sources. 